\title{
LAS CONSECUENCIAS DEL CAMBIO CLIMÁTICO EN EL MAGREB
}

\author{
Mónica Miranzo y Carlos del Río ${ }^{1}$ \\ UNISCI
}

\begin{abstract}
Resumen:
La comunidad internacional cada vez está más preocupada ante el fenómeno del cambio climático. El paso del tiempo ha cambiado la percepción sobre este problema, hasta que en la actualidad es considerado como uno de los principales riesgos para la seguridad internacional. La región del Mediterráneo en general, y el Magreb en particular, es una de las zonas geográficas más vulnerables a nivel global frente al cambio climático, sus efectos y consecuencias. Sus características tanto físicas como humanas, y la presencia de conflictos regionales de difícil solución, agravan los impactos, incrementan las incertidumbres y potencian otros riesgos y amenazas.
\end{abstract}

Palabras clave: cambio climático, calentamiento global, precipitaciones, desertización, aumento del nivel del mar, disponibilidad de agua, seguridad alimentaria, costes de adaptación.

Title in English: "Climate Change's Consequences on the Maghreb Region"

\begin{abstract}
:
International community is increasingly concerned with climate change. Over time, perceptions on this issue have changed, up to the current thread of thought which considers it one of the greatest risks for international security. The Mediterranean region in general, and in particular the Maghreb, is one of the most vulnerable geographic areas to climate change and its consequences. The regional characteristics, both human and physical, as well as the presence of hard-solving regional conflicts, aggravate climate change impacts, increase uncertainties and foster other risks and threats.
\end{abstract}

Keywords: climate change, global warming, precipitations, desertification, sea level rise, water availability, food security, adaptation costs.

Copyright (C) UNISCI, 2015.

Las opiniones expresadas en estos artículos son propias de sus autores, y no reflejan necesariamente la opinion de UNISCI. The views expressed in these articles are those of the authors, and do not necessarily reflect the views of UNISCI.

\footnotetext{
${ }^{1}$ Mónica Miranzo Proy y Carlos del Río son investigadores junior de UNISCI y miembros del Foro HispanoArgelino.

Email: mmiranzop@yahoo.es; carlos_rio86@hotmail.com.

http://dx.doi.org/10.5209/rev_RUNI.2015.n39.51817
} 


\section{Introducción}

El cambio climático se ha erigido durante los últimos años como el gran desafío de nuestro tiempo y la principal amenaza a la salud del planeta, los animales y las personas. En 1992 la Convención Marco de las Naciones Unidas sobre el Cambio Climático reconocía de forma oficial la inquietud de la comunidad internacional por los efectos adversos de los cambios del clima, estableciendo una definición común de cambio climático "un cambio de clima atribuido directa o indirectamente a la actividad humana que altera la composición de la atmósfera mundial y que se suma a la variabilidad natural del clima observada durante períodos de tiempo comparables"2.

Se pone de manifiesto, así, la preocupación creciente por el impacto del uso masivo de combustibles fósiles y la liberación de carbono a la atmósfera que han provocado cambios permanentes en el ecosistema terrestre de carácter gradual, el aumento de temperaturas, el aumento del nivel del mar y los cambios en el ciclo de lluvias y la química de los océanos, y otros de carácter inmediato, el derretimiento del permafrost y el calentamiento de los océanos. Asimismo se reconoce que las consecuencias adversas del cambio climático tienen "efectos nocivos significativos en la composición, la capacidad de recuperación o la productividad de los ecosistemas naturales o sujetos a ordenación, o en el funcionamiento de los sistemas socioeconómicos, o en la salud y el bienestar humanos" ${ }^{3}$.

El impacto del cambio climático en el continente africano y, especialmente, en la región del Magreb, se ha venido analizando de forma cada vez más detallada desde la presentación del Informe Especial del Impacto Regional del Cambio Climático elaborado por el Grupo Intergubernamental de Expertos sobre el Cambio Climático (Intergubernamental Panel on Climate Change, IPCC) ${ }^{4}$ en 1997 sobre la evaluación de la vulnerabilidad. El informe identificaba el cambio climático como un potenciador de riesgos en la región dada la sensibilidad de los recursos hídricos a los parámetros climáticos, asimismo destacaba la necesidad de seguir profundizando en la realización de estudios integrados sobre la materia.

El informe del IPCC del año 2001continúa recalcando la necesidad de profundizar en la extracción de datos y la presentación de informes fiables con análisis comprensivos. Además, detallaba seis sectores de especial vulnerabilidad ante los efectos del cambio climático en el Magreb: recursos hídricos, seguridad alimentaria, recursos naturales y biodiversidad, asentamientos humanos e infraestructuras, salud y desertización. Asimismo alertaba del riesgo que suponía la desertización y el incremento de sequías para la economía regional.

El cuarto informe del IPCC del año 2007 ofrece un salto cuantitativo en la disposición de datos y análisis y presenta las siguientes proyecciones concretas para el futuro de África ${ }^{5}$ :

- Hasta 2020, entre 75 y 250 millones de personas estarían expuestas a un mayor estrés hídrico por efecto del cambio climático.

\footnotetext{
${ }^{2}$ Convención Marco de las Naciones Unidas sobre el Cambio Climático. Naciones Unidas 1992, p. 3, en http://unfecc.int/resource/docs/convkp/convsp.pdf

${ }^{3}$ Ibid, p. 3 .

${ }^{4} \mathrm{~A}$ pesar del prestigio internacional y la fiabilidad de los informes desarrollados por el IPCC, los informes reconocen la existencia de elementos de incertidumbre en las predicciones del cambio climático, especialmente en lo referido a "la distribución cronológica, su magnitud y sus características regionales". El artículo "Cambio Climático: Modelos e impacto en la seguridad alimentaria en el Mediterráneo" de los investigadores David García y Rubén Herrero, publicado en la revista UNISCI Discussion Papers, $\mathrm{n}^{\circ} 31$ (enero 2013), en http://www.ucm.es/unisci, profundiza sobre la fiabilidad de los modelos de cambio climático.

${ }^{5}$ Pachauri Rajendra K. y Reisinger Andy (ed.): "IPCC Cambio climático 2007: Informe de síntesis", Contribución de los Grupos de trabajo I, II y III al Cuarto Informe de evaluación del Grupo Intergubernamental de Expertos sobre el Cambio Climático, IPCC, Ginebra (2007), pp.. 8-10.
} 
- Hasta 2020, la productividad de los cultivos pluviales podría reducirse en algunos países hasta en un 50\%. La producción agrícola y el acceso a los alimentos en numerosos países africanos quedarían en una situación gravemente comprometida. Ello afectaría aún más negativamente a la seguridad alimentaria y exacerbaría la malnutrición.

- Hacia el final del siglo XXI, el aumento proyectado del nivel del mar afectaría a las áreas costeras bajas muy pobladas. El costo de la adaptación podría ascender a, como mínimo, entre un 5\% y un $10 \%$ del producto interno bruto (PIB).

- Hasta 2080, se produciría un aumento de entre un 5\% y un $8 \%$ en la extensión de las tierras áridas y semiáridas en África para toda una serie de escenarios climáticos (RT).

En el caso del Magreb, el informe del IPCC del año 2007 así como el informe presentado por el Plan Bleu en el año 2008 sobre el futuro de la región, ya alertaban de que el Mediterráneo es una de las regiones del mundo en la que el medio ambiente y la actividad humana serán más afectados por el cambio climático y sus efectos multiplicadores, provocando considerables pérdidas en términos económicos y humanos ${ }^{6}$. Las áreas más vulnerables ante la aridez y el estrés hídrico son aquellas cercanas a las zonas desérticas, las zonas costeras y las zonas sometidas a un fuerte crecimiento demográfico ${ }^{7}$.

La preocupación general por las conclusiones alcanzadas en estos informes ha provocado un notable incremento durante los últimos años de la cantidad de literatura científica y estudios sobre los modelos de cambio climático, sus efectos y los costes de adaptación en el Magreb, que ponen de manifiesto la vulnerabilidad de la región frente al cambio climático. El mismo año 2007 la Unión Europea anunciaba la creación del proyecto CIRCE (Climate Change and Impact Reserach: the Mediterranean Environment) para analizar la evolución del cambio climático y sus efectos en la región mediterránea ${ }^{8}$.

Estos análisis ponen de manifiesto el impacto de la actividad humana sobre las transformaciones del clima y su incontestabilidad. El último informe del IPCC del año 2014 tampoco deja lugar a dudas sobre el origen del cambio climático, reconociendo que "La influencia humana en el sistema climático es clara y las recientes emisiones de origen antropógeno de gases de efecto invernadero son las más altas de la historia. (...) Las emisiones continuas de gases de efecto invernadero causarán un mayor calentamiento y cambios duraderos en todos los componentes del sistema climático, lo que hará que aumente la probabilidad de impactos severos, generalizados e irreversibles en las personas y en los ecosistemas." .

El análisis de las consecuencias del cambio climático se ha vuelto especialmente relevante en el caso del continente africano a la vista de las conclusiones del quinto informe del IPCC, cuyos modelos de proyección climática identifican tres riesgos clave en el futuro de la región que afectan al medio ambiente y la actividad humana ${ }^{10}$ :

\footnotetext{
${ }^{6}$ UNEP/Plan Bleu (2008): "The Blue Plan's sustainable development outlook for the Mediterranean", p. 2.

${ }^{7}$ Ibid.p. 2.

${ }^{8}$ Numerosas organizaciones y grupos internacionales han seguido el mismo camino presentando proyectos de investigación en la misma línea.

${ }^{9}$ Cambio Climático 2014. Informe de síntesis. Afirmaciones principales del Resumen para responsables políticos (Grupo Intergubernamental de Expertos sobre el Cambio Climático, IPCC),en http://www.ipcc.ch/news and events/docs/ar5/ar5 syr headlines es.pdf

${ }^{10}$ Cambio climático 2014. Impactos, adaptación y vulnerabilidad. Resumen para responsables de políticas (Contribución del Grupo de trabajo II al Quinto Informe de Evaluación del Grupo Intergubernamental de Expertos sobre el Cambio Climático, IPCC), p. 21 en

https://www.ipcc.ch/pdf/assessment-report/ar5/wg2/ar5 wgII spm es.pdf
} 
- La intensificación del estrés sobre los recursos hídricos que afrontan un importante agotamiento por la sobreexplotación y la degradación en el presente y deberán afrontar una mayor demanda en el futuro, con una agravación a causa del estrés por sequía en las regiones de África propensas a la sequía ${ }^{11}$.

- La reducción de la productividad de los cultivos asociada al estrés por calor y sequía, con fuertes efectos adversos en los medios de subsistencia y la seguridad alimentaria de las regiones, los países y los hogares; también a causa de un mayor daño por plagas y enfermedades y del impacto de las inundaciones en la infraestructura de los sistemas alimentarios $^{12}$.

- Los cambios en la incidencia y el área de distribución geográfica de las enfermedades transmitidas por vectores y por el agua debido a cambios en el promedio y la variabilidad de la temperatura y la precipitación, especialmente en los bordes de sus áreas de distribución ${ }^{13}$.

Además de señalar la situación de inseguridad del continente africano ante las consecuencias del cambio climático, el informe del IPCC reconoce explícitamente el impacto que ya está teniendo el cambio climático en los ecosistemas africanos en la actualidad y la acentuación de sus efectos en el futuro ${ }^{14}$. El cambio climático no es ya un potenciador de riesgos en situaciones de vulnerabilidad o estrés, sino que es, en sí mismo, uno de los mayores riesgos a los que se enfrentarán los países del Magreb en las próximas décadas.

El análisis de los efectos del cambio climático en el Magreb es tan relevante en este caso como las acciones de adaptación y mitigación llevadas a cabo por los responsables políticos, así como una justa evaluación sobre la eficacia de las medidas implementadas en virtud de las recomendaciones del IPCC: "Para controlar el cambio climático sería necesario reducir de forma sustancial y sostenida las emisiones de gases de efecto invernadero, lo cual, junto con la adaptación, puede reducir los riesgos. (...) Muchas opciones de adaptación y mitigación contribuyen a controlar el cambio climático, pero ninguna de ellas basta por sí sola. Para que la implementación de las opciones sea efectiva, se necesitan políticas y cooperación en todas las escalas; y para que estas se fortalezcan, se requieren respuestas integradas que vinculen la adaptación y la mitigación con otros objetivos sociales" ${ }^{15}$.

\section{Características físicas de la región y aspectos poblacionales}

Los países que conforman el Magreb (Marruecos, Argelia, Libia, Túnez y Mauritania) comparten unas características físicas bastante similares, lo que a su vez conlleva que las previsiones de cambio climático a corto, medio y largo plazo analicen el impacto regional global. Las características geográficas y climatológicas más reseñables que hay que tener en cuenta a la hora de abordar el estudio de la zona son las siguientes:

\footnotetext{
${ }^{11}$ Ibid, p. 21.

${ }^{12}$ Ibid, p. 21.

${ }^{13}$ Ibid, p. 21.

${ }^{14}$ Climate Change 2014. Impacts, Adaptation, and Vulnerability. Part B: Regional Aspects (Working Group II Contribution to the Fifth Assessment Report of the Intergovernmental Panel on Climate Change, IPCC). Cambridge University Press p. 1202, en https://ipcc-wg2.gov/AR5/report/full-report/

${ }^{15}$ Cambio Climático 2014. Informe de síntesis. Afirmaciones principales del Resumen para responsables de políticas (Grupo Intergubernamental de Expertos sobre el Cambio Climático, IPCC), en http://www.ipcc.ch/news and events/docs/ar5/ar5 syr headlines es.pdf.
} 
- El desierto del Sáhara ocupa gran parte de la superficie del Magreb: entre el $80 \%$ y el 90\% de Argelia, Mauritania y Libia, el 40\% de Túnez y menos del 25\% de Marruecos ${ }^{16}$. Las precipitaciones anuales son inferiores a los $150 \mathrm{~mm}$ y las temperaturas llegan a superar $\operatorname{los} 40^{\circ} \mathrm{C}$ durante todo el año, con una oscilación térmica muy acusada entre el día y la noche, provocando elevados índices de evaporación del agua que impiden la existencia de cualquier tipo de vegetación fuera de los oasis ${ }^{17}$.

- La franja del litoral, dominada por el clima mediterráneo, se caracteriza por las precipitaciones frecuentes, que en otoño-invierno pueden llegar a los $1000 \mathrm{~mm}$ en algunas áreas, y la baja oscilación térmica, que convierten a esta zona en la más adecuada para el cultivo de la vid, cítricos, frutas y verduras ${ }^{18}$.

- Los altiplanos continentales presentan notables oscilaciones térmicas anuales y precipitaciones que oscilan entre los $400 \mathrm{y}$ los $800 \mathrm{~mm}$, las heladas frecuentes dificultan la práctica de la agricultura, aunque en algunas zonas todavía se cultivan cereales y se mantiene la actividad ganadera ${ }^{19}$.

- En las regiones de interior predomina el clima mediterráneo desértico donde la agricultura es casi inexistente a causa de la acusada caída de precipitaciones, que registran máximos anuales de $150-200 \mathrm{~mm}^{20}$.

Para tener en cuenta los efectos y consecuencias del cambio climático es necesario también considerar las principales características socioeconómicas, geopolíticas y demográficas de la región:

- La población de los países del Magreb, especialmente en el Magreb central (Túnez Argelia y Marruecos), mantiene una dinámica de crecimiento que será constante al menos hasta $2050^{21}$. Además, estos países tienen algunas de las poblaciones más jóvenes del planeta, manteniéndose la media de edad por debajo de los 30 años, con tasas mínimas de población mayor de 65 años y elevados porcentajes de población menor de 15 años 22 .

- A partir de la década de 1980 se ha producido un proceso de urbanización considerable, potenciado por la llegada de oleadas de emigrantes rurales a las ciudades. En la actualidad, la mayor parte de la población de la región se concentra en torno a las áreas urbanas del litoral y, en menor medida, cerca de las principales zonas de cultivo, en las que la densidad de población decrece al tiempo que aumenta la media de edad ${ }^{23}$. Las regiones interiores presentan una densidad de población muy inferior, con zonas desérticas y montañosas mayoritariamente despobladas ${ }^{24}$.

- En paralelo al proceso de urbanización, se ha producido un incremento de rentas generalizado que ha variado los patrones de consumo de la población, incrementando y

\footnotetext{
${ }^{16}$ Segura, Antoni (1994): El Magreb: del colonialismo al islamismo, Barcelona, Universitat de Barcelona, p. 27.

${ }^{17}$ Ibid, p. 28.

${ }^{18}$ Ibid, p. 28.

19 Ibid, p. 28.

${ }^{20}$ Ibid, p. 28.

${ }^{21}$ Abad, Gracia: "Población en el Magreb: situación y dinámicas", UNISCI Discussion Papers, n 31 (enero 2013), en http://www.ucm.es/unisci.

${ }^{22}$ En el mismo artículo mencionado anteriormente la investigadora Gracia Abad expone que, en el año 2011, el $28 \%$ de la población de Marruecos, el 27\% de la de Argelia y el 23\%8 de la de Túnez estaban por debajo de los 15 años de edad según datos del Banco Mundial.

${ }^{23}$ Machín, Nieva y Pardo, Eric: "El envejecimiento de los agricultores en el Magreb", UNISCI Discussion Papers, $\mathrm{n}^{\mathrm{o}} 31$ (enero 2013), en http://www.ucm.es/unisci.

${ }^{24}$ Barras, Raquel: "El incremento de población urbana del Magreb", UNISCI Discussion Papers, no 31 (enero 2013), en http://www.ucm.es/unisci
} 
diversificando la demanda de alimentos hacia productos de mejor calidad ricos en grasas y proteínas ${ }^{25}$.

- La economía regional está fuertemente condicionada por el peso del sector agrícola, cuya actividad se desarrolla mayoritariamente en las franjas costeras ${ }^{26}$. La agricultura supone el 13,25\% del Producto Interior Bruto (PIB) en Marruecos, empleando al 40,3\% de la población total activa, el 12\% del PIB en el caso de Argelia, empleando al 25\% de la población activa y menos del $10 \%$ del PIB en el caso de Túnez ocupando a más del $20 \%$ de la población activa ${ }^{27}$. En el caso de Libia solamente el $2 \%$ del PIB depende de la agricultura ${ }^{28}$.

- La estructura económica del Magreb está notablemente "sectorializada". El sector económico más importante en Libia y Argelia es el de los hidrocarburos que, en el año 2012, representaba el $66 \%$ del PIB y el $95 \%$ de las exportaciones ${ }^{29}$ y el $31,31 \%$ del PIB y casi el $97 \%$ de las exportaciones respectivamente ${ }^{30}$. En el caso de Túnez y Marruecos es el sector servicios el que más peso tiene en la economía y, para el mismo periodo, representaba el $43,1 \%{ }^{31}$ y el $58 \%{ }^{32}$ del PIB respectivamente. Cabe destacar la enorme importancia del turismo dentro del sector servicios marroquí.

- Finalmente no hay que olvidar que, en la actualidad, en el Magreb persisten dos conflictos de gran importancia: el conflicto del Sáhara Occidental y la guerra civil de Libia. Además, durante los últimos años, se ha producido un incremento de la presencia de grupos radicales vinculados al terrorismo yihadista, especialmente constatable con la presencia de Al Qaida en el Magreb Islámico (AQMI) y la aparición del "Estado Islámico".

\section{Cambio climático en el Magreb: cambios observados y tendencias futuras}

Aunque existe un consenso mayoritario entre la comunidad científica acerca del fenómeno del cambio climático y sus consecuencias generales a lo largo del siglo XXI, existen discrepancias acerca de la magnitud y alcance de la variación de las mismas. Los diferentes modelos de cambio climático existentes ofrecen diferentes aproximaciones ${ }^{33}$.

\footnotetext{
${ }^{25}$ Alonso, Antonio: "Incremento de rentas en Argelia, Marruecos y Túnez: ¿Cómo afecta a la seguridad alimentaria?", UNISCI Discussion Papers, no 31 (enero 2013), en http://www.ucm.es/unisci

${ }^{26}$ Barras, op. cit.

${ }^{27}$ García, Javier ; Rodríguez, Patricia y Miranzo, Mónica: "Las políticas agrarias en Túnez, Argelia y Marruecos y la seguridad alimentaria" , UNISCI Discussion Papers, no 31 (enero 2013), en http://www.ucm.es/unisci

${ }^{28}$ Según los datos recogidos por la Oficina Económica y Comercial de España en Trípoli en la "Guía país Libia" solo el 1,7\% de la superficie de Libia es cultivable, representando el sector agrícola libio, en 2010, el 2,09\% del PIB.

${ }^{29}$ Guía País Libia, elaborado por la Oficina Económica y Comercial de España en Trípoli. Actualizado Enero 2012, en

http://www.ibiae.com/sites/default/files/informes-paises/LIBIA $\% 20 \mathrm{Gu} \% \mathrm{C} 3 \% \mathrm{ADa} \% 20 \mathrm{~Pa}$ $\%$ C3\%ADs\%20enero\%202012.pdf, p. 8 .

${ }^{30}$ Guía País Argelia, elaborado por la Oficina Económica y Comercial de España en Argel. Actualizado Octubre 2013, en http://www.comercio.gob.es/tmpDocsCanalPais/7866454A267 0877898BE0F106B 03CFBA.pdf, pp. 11-18.

31 Guía País Túnez, elaborado por la Oficina Económica y Comercial de España en Túnez. Actualizado Septiembre 2013, en

http://www.comercio.gob.es/tmpDocsCanalPais/605062C13 41E88F8F7AF454C64D56E02.pdf, p. 9.

${ }^{32}$ Guía País Marruecos, elaborado por la Oficina Económica y Comercial de España en Rabat. Actualizado Agosto 2013, en http://iberglobal.com/files/marruecos_gp.pdf, pp. 15-16.

${ }^{33}$ El IPCC propone una serie de escenarios que conjugan diferentes factores cuyas correlaciones están comúnmente aceptadas en el marco del estudio del cambio climático, tales como el desarrollo económico, tecnológico y demográfico, así como el contexto político general tanto interno como internacional. A lo largo del tiempo, estos escenarios han ido evolucionando de aproximaciones lineales ascendentes, en las que se partía de
} 
Los modelos de cambio climático aportan una gran diversidad de enfoques a la hora de abordar el estudio tanto de la evolución global, como de la evolución regional del cambio climático. La diversidad entre los enfoques de los diferentes modelos de cambio radica en el peso que dan a determinados factores dentro de las progresiones matemáticas y la resolución horizontal y vertical aplicadas. Así, por ejemplo, contemplamos modelos de cambio como las simulaciones WCRP CMIP3 (World Climate Research Programme, Coupled Model Intercomparison Project phase 3), que intenta generar simulaciones en escenarios realistas para observar la evolución de la climatología pasada, presente y futura en diversas regiones ${ }^{34}$, o los modelos propuestos por el proyecto europeo PRUDENCE (Prediction of Regional Scenarios and Uncertainties for Defining European Climate Change Risks and Effects), cuyo objetivo era el estudio de las consecuencias del cambio climático en el marco geográfico europeo $^{35}$.

No obstante, algunos de los modelos propuestos y su aplicación a los diversos ámbitos geográficos han sido criticados por su insuficiencia en la consideración de las características físicas y humanas específicas de los diversos ámbitos geográficos de estudio, disminuyendo la fiabilidad o precisión de las conclusiones ${ }^{36}$. En el ámbito regional del Mediterráneo y el Magreb el modelo CIRCE propone un enfoque multidisciplinar, aplicando una alta resolución geográfica conjugada con el estudio de la mayor cantidad de variables posibles ${ }^{37}$.

Independientemente de las diferencias de los modelos de cambio climático disponibles, existe un consenso generalizado acerca de las consecuencias del cambio climático detectadas: un aumento progresivo de las temperaturas, tanto durante la época estival como durante la invernal, un mayor descenso y concentración estacional en las precipitaciones y un incremento en frecuencia de fenómenos atmosféricos extremos.

\subsection{Incremento de temperaturas}

Los modelos de cambio climático arrojan diferentes resultados sobre el aumento de las temperaturas en los diversos escenarios propuestos. No obstante, se puede observar que según avanzan los modelos en el tiempo, las previsiones tienden a vaticinar cada vez un mayor aumento de temperaturas. Así, en 2008-2009, expertos árabes aceptaban modelos que auguraban un aumento de temperaturas que oscilaba entre $\operatorname{los} 2^{\circ} \mathrm{C}$ hasta $\operatorname{los} 5.5^{\circ} \mathrm{C}$ hasta $2050^{38}$, mientras que un informe del Consejo Nacional de Inteligencia de los EE.UU., incluía un aumento de temperaturas de $3.2^{\circ} \mathrm{C}$ en época invernal y de hasta $4.1^{\circ} \mathrm{C}$ en época estival, en el marco del escenario de emisiones $\mathrm{A}_{1 \mathrm{~B}^{39}}$.

la observación de la evolución del clima históricamente (escenarios A1 y B2, por ejemplo), hasta los modelos más recientes, denominados "híbridos" en los que se parte de una base compuesta por variables pertenecientes a diferentes escenarios y las combinan para finalmente ofrecer predicciones que se ajustan de forma en principio más precisa a la variabilidad climatológica (escenario A1B, por ejemplo). Los resultados arrojados son posteriormente clasificados según una escala de probabilidad de que se cumplan.

34 World Climate Research Programme, "Coupled Model Intercomparison Project phase 3 Overview, en http://cmip-pcmdi.llnl.gov/cmip3_overview.html?submenuheader=1

${ }_{35}$ Christensen, Jens Hesselbjerg (coord.): "Prediction of Regional Scenarios and Uncertainties for Defining European Climate Change Risks and Effects", Febrero 2005, en:

http://prudence.dmi.dk/public/publications/PRUDENCE\%20Final\%20report.pdf

${ }^{36}$ Navarra, Antonio y Tubiana, Laurence (eds.) ((2013): "Regional Assessment of Climate Change in the Mediterranean. Volume 1: Air, Sea and precipitation and Water", Heidelberg, New York, London, Springer, p.58

${ }^{37}$ Ibid, pp. 59-60

${ }^{38}$ Tolba, Mostafa K. y Saab, Najib W. : "Arab Environment, Future Challenges", AFED, Beirut (2008), p. XI

${ }^{39}$ National Intelligence Council, op. cit., p. 16 
Al mismo tiempo, algunos autores han enmendado sus predicciones iniciales. Los modelos realizados en 2004 por los investigadores de Castro, Gallardo y Calabria ${ }^{40}$, que preveían un aumento de temperaturas de hasta $6^{\circ} \mathrm{C}$ y $5^{\circ} \mathrm{C}$ en $\operatorname{los}$ escenarios $\mathrm{A} 2$ y $\mathrm{B} 2$ respectivamente en época estival (con una diferencia de un aumento de $1-2^{\circ} \mathrm{C}$ inferior en época invernal), fueron posteriormente señalados como demasiado optimistas por sus autores ante la ausencia de políticas de mitigación ${ }^{41}$. Al mismo tiempo, otros investigadores que utilizaban modelos diferentes preveían un aumento de temperaturas de entre $1.2^{\circ} \mathrm{C}$ hasta $1.5^{\circ} \mathrm{C}$ en el marco del escenario $\mathrm{A} 1 \mathrm{y}$ de $3.1^{\circ} \mathrm{C}$ a $4.4^{\circ} \mathrm{C}$ en el escenario $\mathrm{A} 2^{42}$.

Modelos de mayor resolución regional y enmarcados en escenarios más moderados como los utilizados por CIRCE, en sus representaciones para 2021-2050, llegaron a la conclusión de que la temperatura en el sur del Mediterráneo subiría entre $1-1.5^{\circ} \mathrm{C}$ en época invernal y $1.75-2^{\circ} \mathrm{C}$ en época estival ${ }^{43}$.

El quinto informe del IPCC pone de manifiesto que, durante las últimas décadas, las temperaturas en el continente africano han sufrido un incremento mínimo de $0.5^{\circ} \mathrm{C}^{44}$ y es muy probable que sigan aumentando en los próximos años de forma más acelerada que la media global $^{45}$. En la región magrebí, se ha puesto de manifiesto que el aumento de temperaturas contrastado, especialmente acentuado a partir de 1970, ha sobrepasado las fluctuaciones climáticas naturales derivadas de la variabilidad interna ${ }^{46}$.

Esta tendencia es especialmente acusada en países como Argelia y Marruecos durante las estaciones cálidas ${ }^{47}$ y se prevé que durante el próximo siglo seguirá produciéndose un aumento mínimo de $2^{\circ} \mathrm{C}$, llegando hasta $\operatorname{los} 6^{\circ} \mathrm{C}$ en algunas proyecciones ${ }^{48}$, que se hará notar sobre todo en un ascenso continuado de las temperaturas mínimas. En el caso del desierto del Sahara, el aumento de temperaturas estaría relacionado con el incremento de olas de calor durante los próximos años ${ }^{49}$ (véase Figura 1).

Figura 1

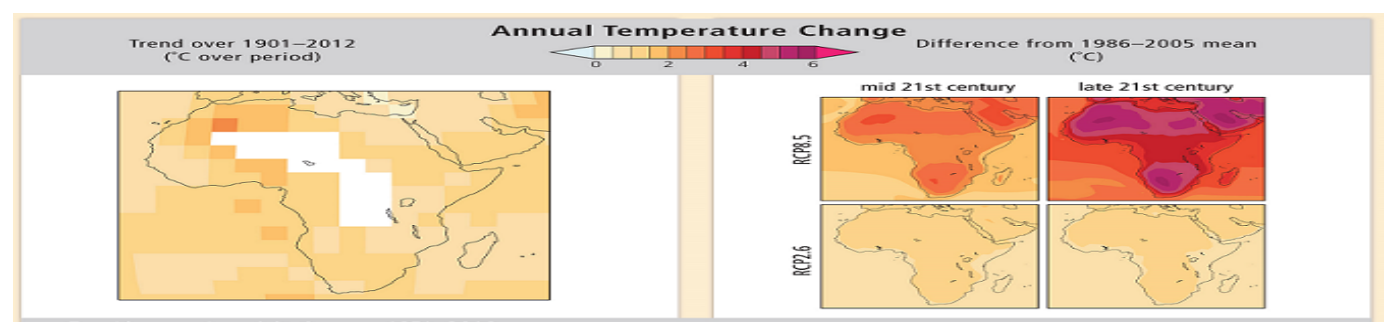

Fuente: Fifth Assessment Report of the IPCC ${ }^{50}$.

\footnotetext{
${ }^{40}$ De Castro, M., Gallardo C. y Calabria S. : "Regional IPCC Projections until 2100 in the Mediterranean Area", en Marquina, Antonio (ed.) (2004): Environmental Challenges in the Mediterranean 2000-2050, Dordrecht, Boston London, Kluwer Academic Publishers (2004), pp 75-90

41 Marquina, Antonio: "Prospects for Environmentaly-Induced Migration from Southern and Eastern Mediterranean to the European Union", en Marquina, Antonio (ed.) (2011): Perspectives of Migration Flows in Asia and Europe, UNISCI-ASEF, p. 238.

${ }^{42}$ Ibid, p. 238.

${ }^{43}$ Navarra, Antonio y Tubiana, Laurence (eds.), op. cit., p. 71.

${ }^{44}$ Climate Change 2014. Impacts, Adaptation, and Vulnerability. Part B.., op. cit., p. 1206.

${ }^{45}$ Ibid, p. 1206.

${ }^{46}$ Ibid, p. 1206.

${ }^{47}$ Ibid, p. 1206.

${ }^{48}$ Ibid, p. 1206.

${ }^{49}$ El informe del IPCC recoge que el área del noroeste del Sahara ha experimentado una media de 40 a 50 días de ola de calor entre 1989 y 2009.

${ }^{50}$ El escenario RCP2.6 es relativo concentraciones mínimas de gases de efecto invernadero en la atmósfera, alcanzadas mediante una reducción de emisiones a lo largo del tiempo. El escenario RCP8.5 es relativo a
} 


\subsection{Caída de precipitaciones}

Manteniendo la continuidad con las fuentes utilizadas para señalar algunos modelos como ejemplos para la subida de temperaturas, podemos señalar que los mismos expertos árabes aceptaban un descenso en las precipitaciones de entre un $0 \%$ y un $20 \%$ hasta $2050^{51}$. El citado informe del Consejo Nacional de Inteligencia del año 2009, aceptada previsiones para el escenario $\mathrm{A} 1 \mathrm{~B}$ de un descenso del $18 \%$ en época invernal y del $6 \%$ en época estival ${ }^{52}$. Asimismo, los modelos utilizados por CIRCE prevén un descenso de las precipitaciones de entre el 5\%-10\% para la época invernal y entre el 10-15\% para la época estival ${ }^{53}$.

Los resultados del último informe del IPCC evidencian que el Magreb ha experimentado un descenso significativo del nivel anual de precipitaciones, especialmente durante el invierno y la primavera, llegando contabilizar períodos superiores a los 330 días secos (precipitaciones inferiores a $1 \mathrm{~mm}$ al día) ${ }^{54}$ por año entre 1997 y 2008 en el norte del Atlas y la costa de Argelia y Túnez. Sin embargo, la tendencia de las precipitaciones ha sido positiva en algunas zonas de Argelia y Marruecos y se ha mantenido estable en el Sáhara ${ }^{55}$ (véase Figura 2)

La caída de precipitaciones será una constante a lo largo de este siglo, que según algunas previsiones, podría suponer un descenso de hasta el $27 \%$ antes del año $2050^{56}$. Además, los ciclos de precipitaciones sufrirían alteraciones severas, aumentando su concentración estacional y su intensidad y exagerando los períodos de sequía. Algunos estudios señalan que hacia finales de este siglo 1 de cada 2 años podría ser completamente seco $^{57}$ en países como Argelia, Libia, Túnez y la zona norte de Marruecos.

Figura 2

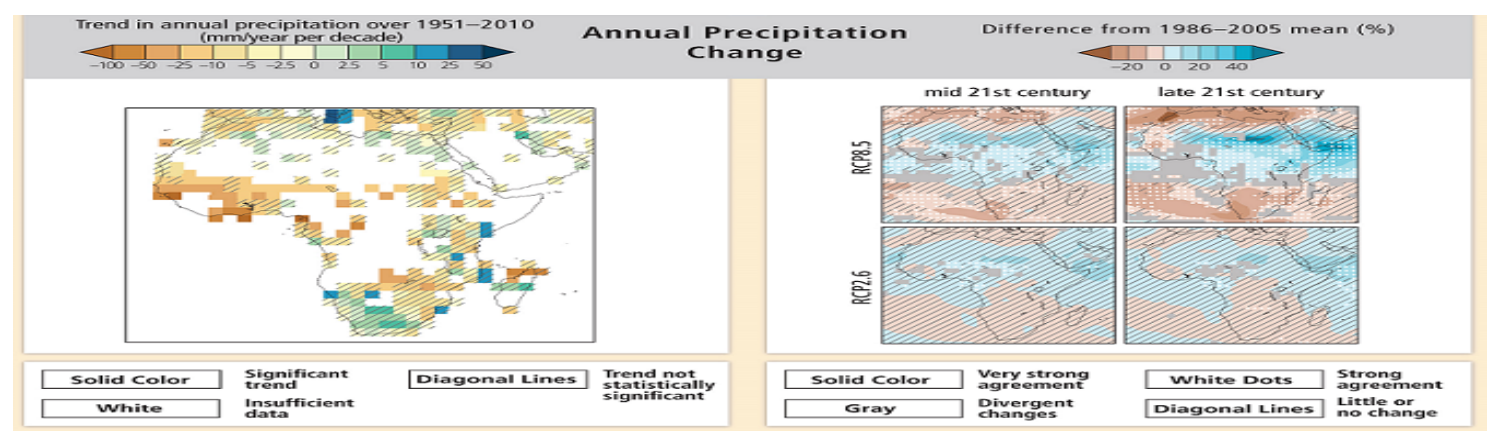

Fuente: Fifth Assessment Report of the IPCC ${ }^{58}$.

La inestabilidad climática magrebí se acentuará en las próximas décadas provocando la intensificación de fenómenos meteorológicos extremos, especialmente el aumento en

concentraciones elevadas de gases de efecto invernadero en la atmósfera, alcanzadas mediante el aumento de las emisiones a lo largo del tiempo.

${ }^{51}$ Tolba, Mostafa K. y Saab, Najib W., op. cit., p. XI

${ }^{52}$ National Intelligence Council, op. cit., p. 16

${ }^{53}$ Navarra, Antonio y Tubiana, Laurence (eds.), op. cit., p. 71.

${ }^{54}$ Climate Change 2014. Impacts, Adaptation, and Vulnerability. Part B, op. cit., p. 1209.

${ }^{55}$ Ibid, p. 1210.

${ }^{56}$ Iiddri-Meedat: "The Future of the Mediterranean: From Impacts of Climate Change to Adaptation Issues Institute for Sustainable Development and International Relations", (Sci-Po)-Congrès International des Réseaux Electriques de Distribution (2009).

${ }^{57}$ Ibid.

${ }^{58}$ Ver nota 36. 
frecuencia e intensidad de seguías ${ }^{59}$, inundaciones y lluvias torrenciales altamente estacionales que multiplicarán los impactos negativos sobre la vida y la actividad humana.

\section{El estado de los recursos hídricos en el Magreb}

En el contexto del cambio climático, el acceso a fuentes de agua para su utilización en los ámbitos agrícola, industrial y doméstico supone uno de los mayores desafíos para el futuro. Como declaró el Vicesecretario General de Naciones Unidas Jan Eliasson en marzo de este año, "el agua es un prerrequisito para la existencia humana"60.

La región del Mediterráneo es especialmente vulnerable a los efectos del cambio climático sobre la disponibilidad de agua y el acceso a la misma. La región concentra el 7.3\% de la población mundial, mientras que solo dispone de acceso al 3\% de las fuentes de agua dulce del planeta ${ }^{61}$. Actualmente, 30 millones de personas concentradas en las riberas oriental y meridional de la región, para 2025 está previsto que sean 60 millones, no disponen de ningún acceso a agua potable en la región ${ }^{62}$ (véase Figura 3).

Figura 3

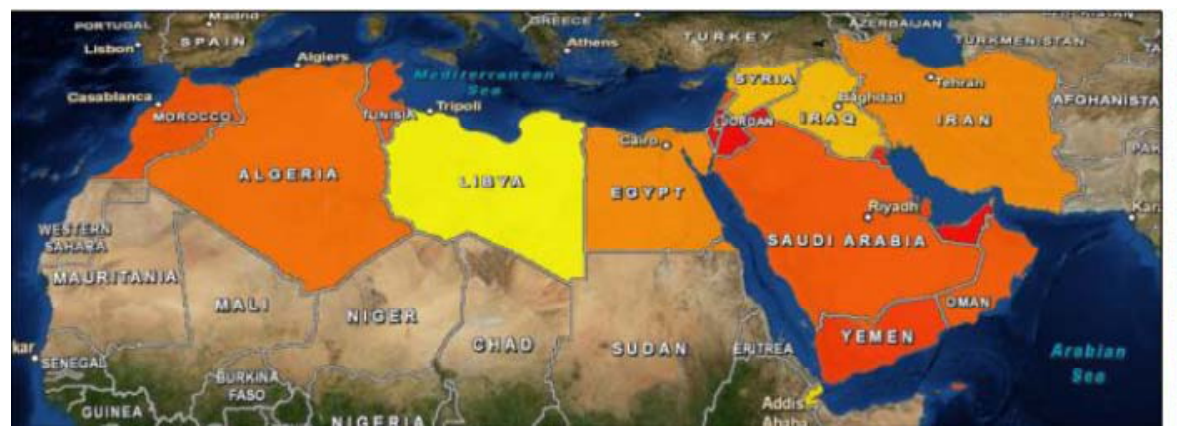

Water availability (m3/capita)!

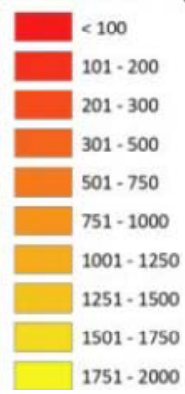

Fuente: Water resources trends in Middle East and North Africa towards $2050^{63}$.

Las tres principales fuentes de consumo de agua en la región del Magreb son, por orden de mayor a menor peso, la agricultura, el uso doméstico y la industria. Estos datos son coherentes con los expuestos por el Climate Institute, siendo la media de consumo de agua destinada a la agricultura, a nivel mundial en 2005 , un $67 \%$ del total disponible ${ }^{64}$ (véase Figura 4):

\footnotetext{
${ }^{59}$ Climate Change 2014. Impacts, Adaptation, and Vulnerability. Part B.., op. cit., p. 1136.

${ }^{60}$ World Water Day: 2015 Water and Sustainable Development, en https://www.youtub e.com/watch?v=FLeel8PfOxw\&list=UUhX9iJfMSEvk3aUDGsxIN1Q, a través de http://ww w.unwater.org/news-events/news-details/en/c/281009/

${ }^{6}$ Navarra, Antonio y Tubiana, Laurence (eds.) (2013): Regional Assessment of Climate Change in the Mediterranean. Vol I Air, Sea, And Precipitation and Water, Heidelberg, New York, London, Springer

${ }^{62}$ Ibid.

${ }^{63}$ Droogers, P., Immerzeel, W.W., Terink, W., Hoogeveen, J., Bierkens, M. F. P., van Beek, L. P. H. y Debele, B., "Water resources trends in Middle East and North Africa towards 2050", Hydrol. Earth Syst. Sci (Septiembre 2012).

${ }^{64}$ Water, en http://www.climate.org/topics/water.html
} 
Figura 4

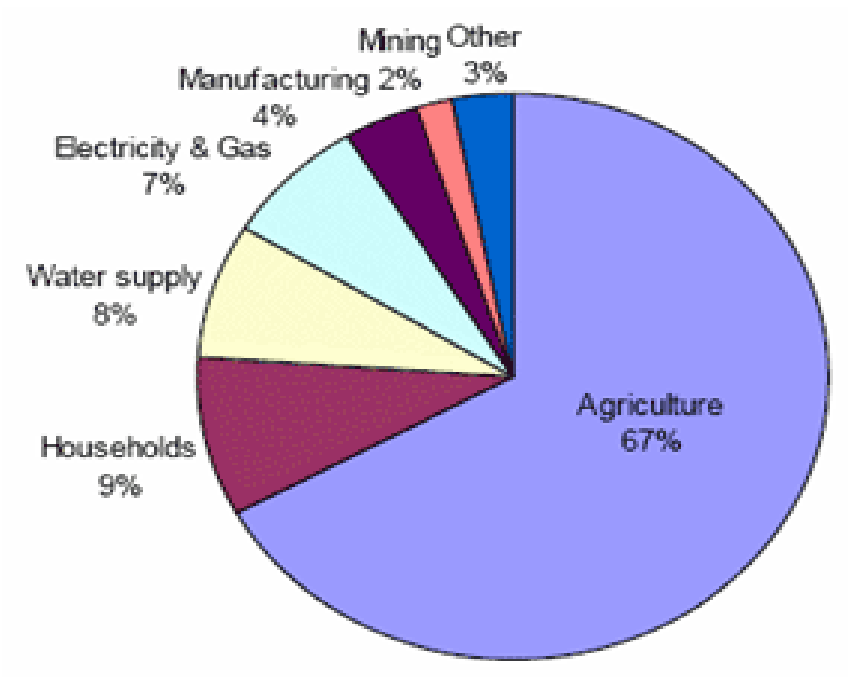

Fuente: Climate Institute.

No obstante, según datos de la United Nations Environment Programme (UNEP), en Marruecos, Túnez y Libia el consumo de agua destinada a la agricultura supera el $79 \%$ del total disponible en dichos países, mientras que en Argelia se mantiene un poco por debajo de la media global $^{65}$.

El consumo doméstico supone actualmente la segunda fuente de mayor consumo en la región, y las previsiones relativas al aumento de la tasa de urbanización, junto con el crecimiento demográfico $^{66}$, no harán sino aumentar la demanda de agua para uso doméstico a nivel regional.

La disponibilidad de agua en la región se verá afectada no tanto a consecuencia del cambio climático como por otros factores como el crecimiento demográfico, la urbanización, el incremento de la actividad agrícola y los cambios en la utilización de tierras. De hecho, el quinto informe del IPCC prevé que para 2050, el $22 \%$ de la escasez de agua en el Norte de África sea consecuencia del cambio climático, mientras que el $78 \%$ restante sea consecuencia de otros factores ${ }^{67}$. La evolución de estos factores influirá directamente sobre las dinámicas de consumo y la disponibilidad de agua en la región, incluyendo una explotación cada vez mayor de fuentes no renovables ${ }^{68}$, que ya son sobre-explotadas en muchas áreas de la región ${ }^{69}$ (véase Figura 5).

\footnotetext{
${ }^{65}$ UNEP, Freshwater use by sector at the beginning of the 2000s, en http://www.unep.org/dew a/vitalwater/article48.html

${ }^{66}$ Machín y Pardo, op cit.

${ }^{67}$ Climate Change 2014. Impacts, Adaptation, and Vulnerability. Part B.., op. cit., p. 1217.

${ }^{68}$ Les perspectives du Plan Bleu sur le développement durable en Méditerranée, Plan Bleu, Sophia Antipolis 2008, en http://www.circle-med.net/doc/MSDoutlook fr.pdf.

${ }^{69}$ García, David y Herrero, Rubén: "Cambio Climático: Modelos e impacto en la seguridad alimentaria en el Mediterráneo", UNISCI Discussion Papers, no 31 (enero 2013), en http://www.ucm.es/info/unisci.
} 
Figura 5

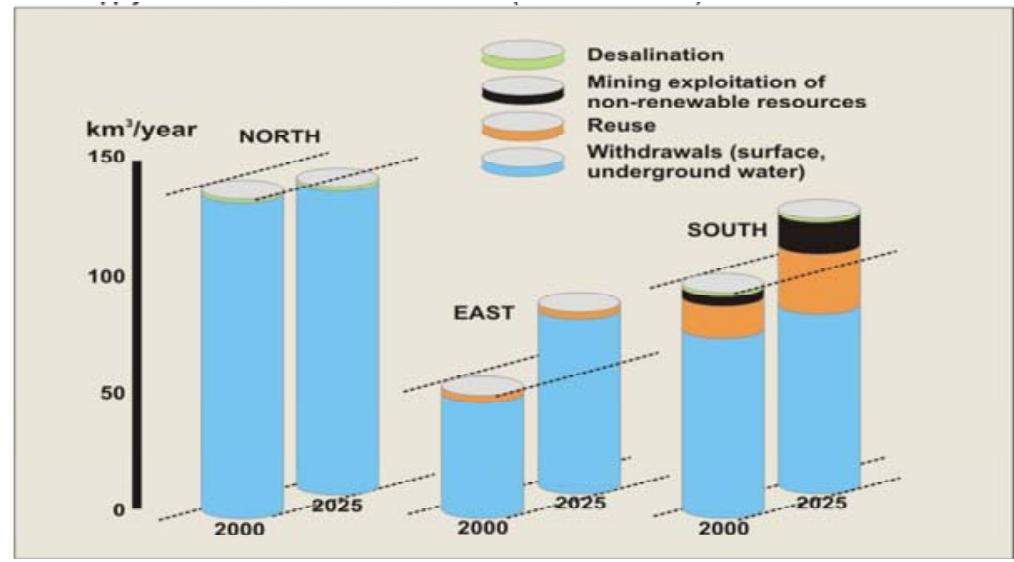

Fuente: Plan Bleu.

En este contexto, la logística relativa a la canalización y el almacenamiento del agua resultan fundamentales para garantizar el acceso a fuentes de agua dulce ${ }^{70}$. Para alcanzar tal fin la inversión en tecnologías que permitan un correcto y eficaz almacenamiento de agua resultan fundamentales, y no hay que perder de vista que a nivel global, la UNEP considera que en la actualidad, se pierde más agua almacenada de la que se llega a utilizar para uso doméstico e industrial $^{71}$ (véase Figura 6).

Figura 6

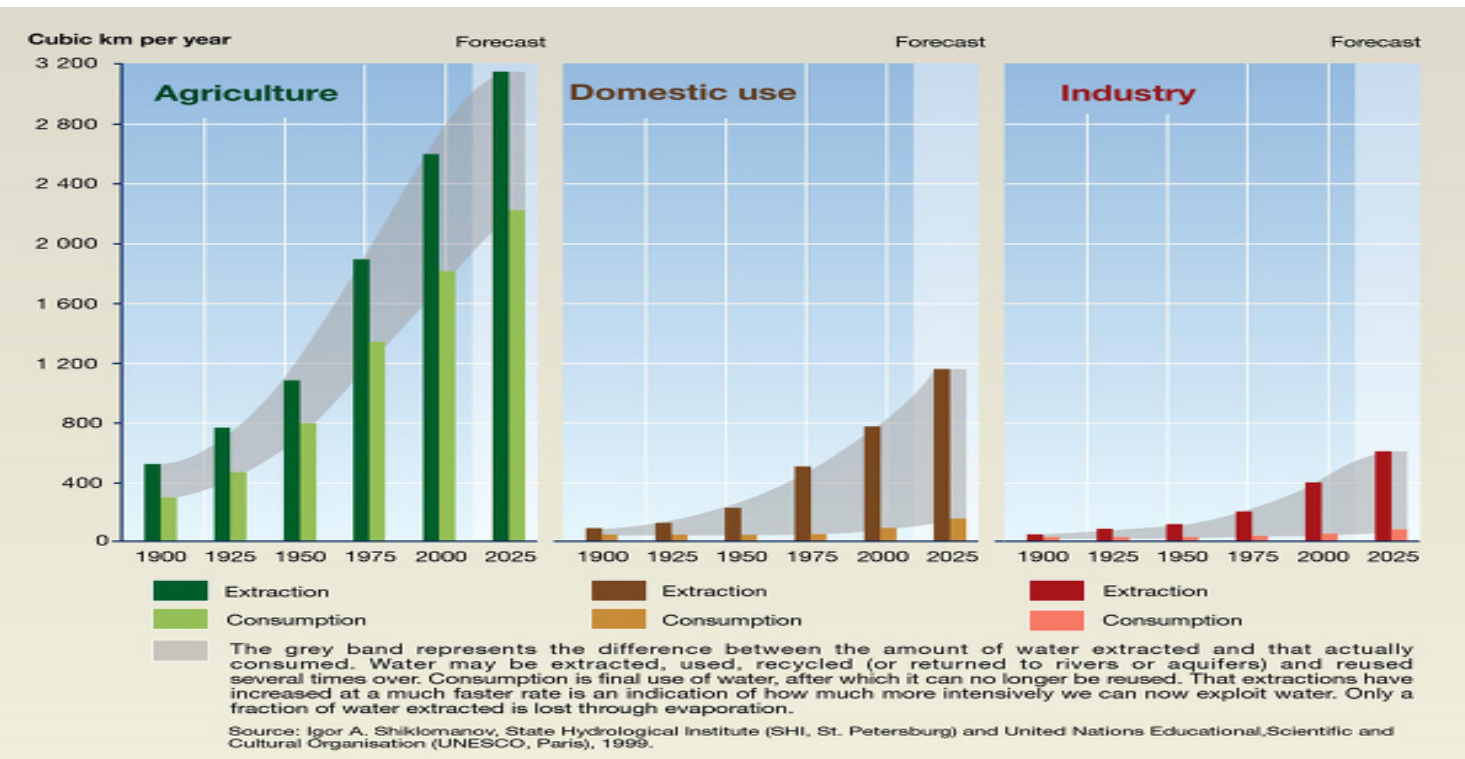

Fuente: UNEP.

\footnotetext{
${ }^{70}$ Impact of Climate Change on the Arab World

${ }^{71}$ UNEP, Water withdrawal and consumption: the big gap, en http://www.unep.org/dew a/vitalwater/article42.html.
} 
A nivel regional, partiendo de la base en que los recursos son escasos, la ineficiencia en ese aspecto puede resultar catastrófica ${ }^{72}$. Las capacidades de almacenamiento de agua en la región no están preparadas para afrontar las necesidades del futuro (véase Tabla 1):

Tabla 1

\begin{tabular}{|l|c|c|c|}
\hline & $\begin{array}{l}\text { Indice de } \\
\text { Capacidad de } \\
\text { Almacenamiento }\end{array}$ & $\begin{array}{l}\text { Recursos hídricos: } \\
\text { Total Renovación } \\
\text { Interna }\end{array}$ & $\begin{array}{l}\text { Eficiencia en la } \\
\text { Utilizacióndel Agua }\end{array}$ \\
\hline Argelia & 0.53 & 11.25 & 37 \\
\hline Marruecos & 0.55 & 29 & 42 \\
\hline Túnez & 0.61 & 4.195 & 60 \\
\hline
\end{tabular}

Fuente: Climate Change Compounding Risks in North Africa.

Las proyecciones indican un descenso progresivo en las previsiones de disponibilidad de agua, observándose una importante disminución en las reservas de agua renovables a medio plazo. En el año 2010 Argelia, Libia, Marruecos y Túnez disponían de reservas renovables por debajo de la barrera del estrés hídrico, sin embargo, se prevé que para el año 2030, las reservas de estos países, excepto en el caso de Marruecos, habrán disminuido hasta niveles de escasez total de agua, inferiores a los 500 metros cúbicos de agua por habitante/año ${ }^{73}$ (véase Figura 7).

Figura 7

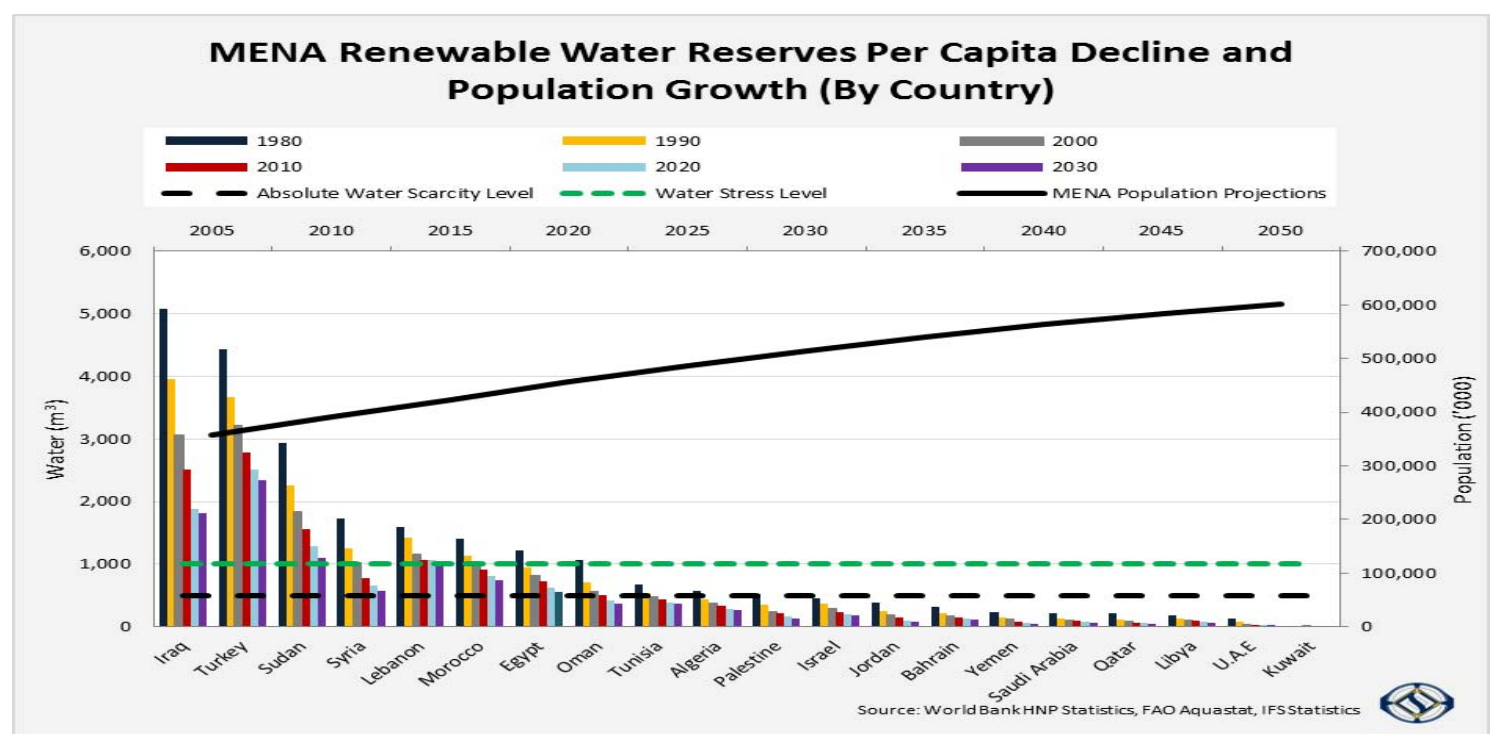

Fuente: Water Scarcity in the MENA Region.

\footnotetext{
${ }^{72}$ Drine, Imed, (2011) "Climate Change Compounding Risks in North Africa", United Nations University, UNUWIDER, Working Paper 2011/32 (2011), en http://www.wider. unu.edu/publications/working-papers/2011/en_GB/wp2011-032/

73 "Water Scarcity in the MENA Region", Signet Institute, Mayo 2013, P.1
} 
También se está agravando la disminución de la disponibilidad de agua superficial. En el caso de Marruecos, se calcula que la reducción en el caudal de los ríos lleve a que la mayoría sean deficitarios para $2020^{74}$, mientras que en Argelia existe una disminución progresiva de la disponibilidad total de agua superficial, pasando de 13,5 mil millones de m3/año a finales de la década de 1970, a los 12 mil millones de m3/año en los años ochenta y a los 10 mil millones de m3/año en los años $2000^{75}$.

\section{Impactos del cambio climático}

Utilizamos el término impactos para referirnos a los efectos sobre los sistemas naturales y humanos de episodios meteorológicos y climáticos extremos y del cambio climático. El quinto informe del IPCC define "impactos" como "efectos en las vidas, medios de subsistencia, salud, ecosistemas, economías, sociedades, culturas, servicios e infraestructuras debido a la interacción de los cambios climáticos o fenómenos climáticos peligrosos que ocurren en un lapso de tiempo específico y a la vulnerabilidad de las sociedades o los sistemas expuestos a ellos"76.

\subsection{Impactos sobre los sistemas naturales e impactos físicos}

\subsubsection{Desertización y degradación de la tierra}

La Convención de las Naciones Unidas para la Lucha contra la Desertificación define en su Artículo $1^{\circ}$ la desertificación como: "la degradación de las tierras en las zonas áridas, semiáridas y subhúmedas secas resultante de diversos factores tales como las variaciones climáticas y las actividades humanas"77. En el Magreb, durante los últimos años, ha tenido lugar un proceso de erosión y degradación del suelo, de forma especialmente intensa en las áreas más secas, que continuará durante las próximas décadas con graves efectos sobre la biodiversidad, la pérdida de productividad de la tierra y la contracción de la frontera agrícola de la región. Actualmente, se calcula que el $57 \%$ de la superficie del Norte de África está amenazada por la desertización ${ }^{78}$.

Si bien el fenómeno de la desertización y la degradación de la tierra se agrava por el impacto del cambio climático, este responde a causas principalmente humanas: el sobrepastoreo y la sobreexplotación de la tierra, la deforestación y la falta de irrigación entre otras $^{79}$. A esto hay que añadir el impacto de los incendios, las sequías y el incremento previsible de las riadas e inundaciones. El aumento de los niveles de desertización y

\footnotetext{
${ }^{74}$ M. Ait, Kadi: "From Water Scarcity to Water Security in the Magherb Region. The Moroccan Case", en Marquina Antonio (ed.) (2004): Environmental challenges in the Mediterranean 2000-2050, Dordrecht, Kluwer Academic.

${ }^{75}$ Zareb, Djamel: "Les programmes de développement en eau dans la stratégie de développement de la sécurité alimentaire en Algérie", Presentación en la Facultad de Ciencias Políticas y Sociología de Madrid (30 de octubre 2012)

${ }^{76}$ Cambio climático 2014. Impactos, adaptación y vulnerabilidad. Resumen para responsables de políticas (Contribución del Grupo de trabajo II al Quinto Informe de Evaluación del Grupo Intergubernamental de Expertos sobre el Cambio Climático, IPCC). p. 5, en https://www.ipcc.ch/pdf/assessment-report/ar5/wg2/ar5_wgII_spm_es.pdf

${ }^{77}$ Convención de las Naciones Unidas para la Lucha contra la Desertificación, en http://www.unccd.int/Lists/SiteDocumentLibrary/Parliament/2003/PDUNCCD(spa).pdf

${ }_{78}$ Marquina, Antonio "Global Warming and Climate Change. Prospects and Policies in Asia and Europe", Palgrave-MacMillan. Chapter 11.

${ }^{79}$ The relationship between desertification and climate change in the Mediterranean, Aston Centre for Europe Aston University, 2011, p. 5, en http://cor.europa.eu/en/documentation/studies/Documents/relationship-desertification-climate-change.pdf
} 
degradación de la tierra y la pérdida de tierras cultivables ${ }^{80}$ tiene consecuencias adversas sobre la capacidad de resistencia de la tierra a la variabilidad del clima y sobre la productividad de los cultivos y la actividad ganadera, con efectos multiplicadores sobre la inseguridad alimentaria de la región ${ }^{81}$ y la inestabilidad socio-económica ${ }^{82}$.

El incremento de las temperaturas y de los niveles de evaporación de agua y la caída de precipitaciones ha repercutido notablemente en la reducción de los niveles de humedad del suelo. A largo plazo, el incremento en los niveles de desertización en Argelia, Túnez, Libia y Marruecos (véase Figura 8) provocará la disminución de las disponibilidades de agua, que ya se acerca o es menor de los $1000 \mathrm{~m} 3$ por persona/año ${ }^{83}$. A las pérdidas de biodiversidad debemos añadir los costes económicos derivados de los costes de adaptación y la lucha por los recursos ${ }^{84}$.

\section{Figura 8}

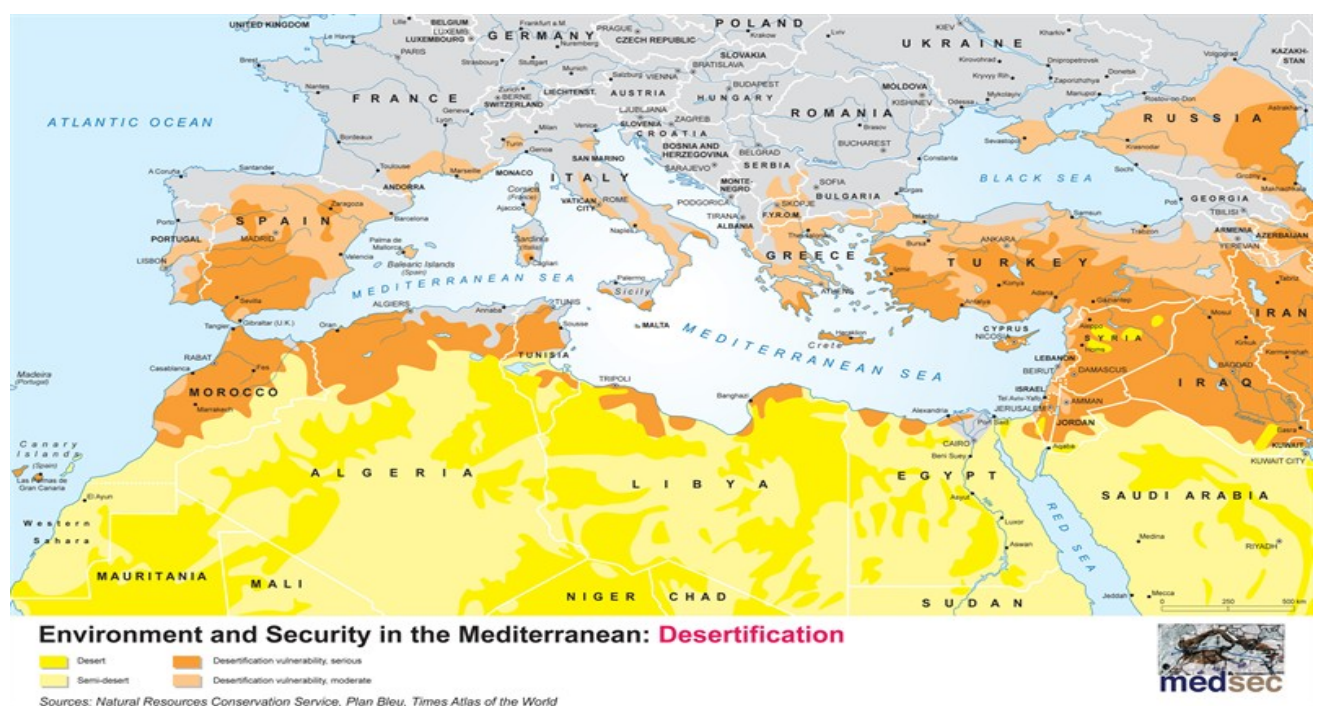

Fuente: Natural Resources Conservation Service, Plan Bleu, Times Atlas of the World 2009.

De todos los países del Magreb es Libia es que está enfrentando el mayor riesgo de desertización $^{85}$, seguido de Marruecos y Túnez, en el caso de Argelia, el Ministerio de Agricultura y Desarrollo rural estima que más de un $20 \%$ de la superficie total del país, alrededor de 50 millones de hectáreas de tierras están amenazadas por la erosión y desertización ${ }^{86}$. El avance del desierto del Sáhara absorbe 40.000 hectáreas de tierra cultivable en Argelia cada año, Marruecos pierde 22.000 hectáreas y Túnez 8.000. En la actualidad más

\footnotetext{
${ }^{80}$ Se predice que la zona del África subsahariana será la más afectada por la pérdida de tierras cultivables ( 2,3 millones de km2) seguida de Oriente Medio y el Norte de África ( 1,8 millones de km2) Véase " Climate change to shift global spread and quality of agricultural land", Science for Environment Policy, Issue 403, 12 February 2015.

81 "Mediterranean land degradation threatens food security", Science for Environment Policy, Issue 391, 30 October 2014.

82 The relationship between desertification and climate change in the Mediterranean, Aston Centre for Europe Aston University, 2011, p. 6.

${ }^{83}$ Ibid, p. 7.

${ }^{84}$ Ibid, p. 9.

${ }^{85}$ El Shaer, Hassan M.: "Land desertification and restoration in Middle East and North Africa (MENA) región", Sciences in Cold and Arid Regions, Volume 7, Issue 1, (February, 2015), p. 9, en http://www.scar.ac.cn

${ }^{86}$ Naili Mohamed: "Désertification, érosion hydrique et dégradation des sols: plus de 50 millions d'hectares menacés en Algérie" El Watan, 7 mayo 2012, en http://www.elwatan.com/economie/plus-de-50-millions-dhectares-menaces-en-algerie-07-05-2012-169579 111.php.
} 
del $80 \%$ de la superficie argelina forma ya parte del desierto del Sáhara y entre 1996 y 2006 se perdieron $130.000 \mathrm{~km} 2$ por el avance del desierto, debido tanto a prácticas forestales agresivas con el medioambiente como a los efectos del cambio climático, provocando la degradación de las llanuras semiáridas al norte del desierto del Sáhara ${ }^{87}$ y aumentando la presión demográfica sobre la franja costera.

\subsubsection{Subida del nivel del mar}

Entre los principales efectos del aumento de temperaturas global detectado en el último siglo destaca el impacto sobre la expansión térmica del agua marina y el derretimiento de los glaciares que han provocado un aumento, cada vez más acelerado, del nivel del mar, pasando de incrementarse una media de $1,7 \mathrm{~mm} /$ año entre 1901 y 2010 hasta los 3,2 mm/año entre 1993 y $2010^{88}$.

Existe una certeza casi universal de que el nivel del mar continuará subiendo durante este siglo hasta alcanzar entre los 0.28 y los 0.61 metros en el escenario más favorable y llegando hasta 1 metro en el más desfavorable ${ }^{89}$ (véase Figura 9) afectando a 41.500 kilómetros cuadrados de costa de países árabes incluidos Marruecos, Túnez y Argelia ${ }^{90}$. En los próximos siglos los niveles de subida del mar oscilan entre menos de 1 metro, en el escenario más favorable, hasta los 7 metros en la proyección más catastrófica asociada a un aumento de $4^{\circ} \mathrm{C}$ en las temperaturas.

Figura 9

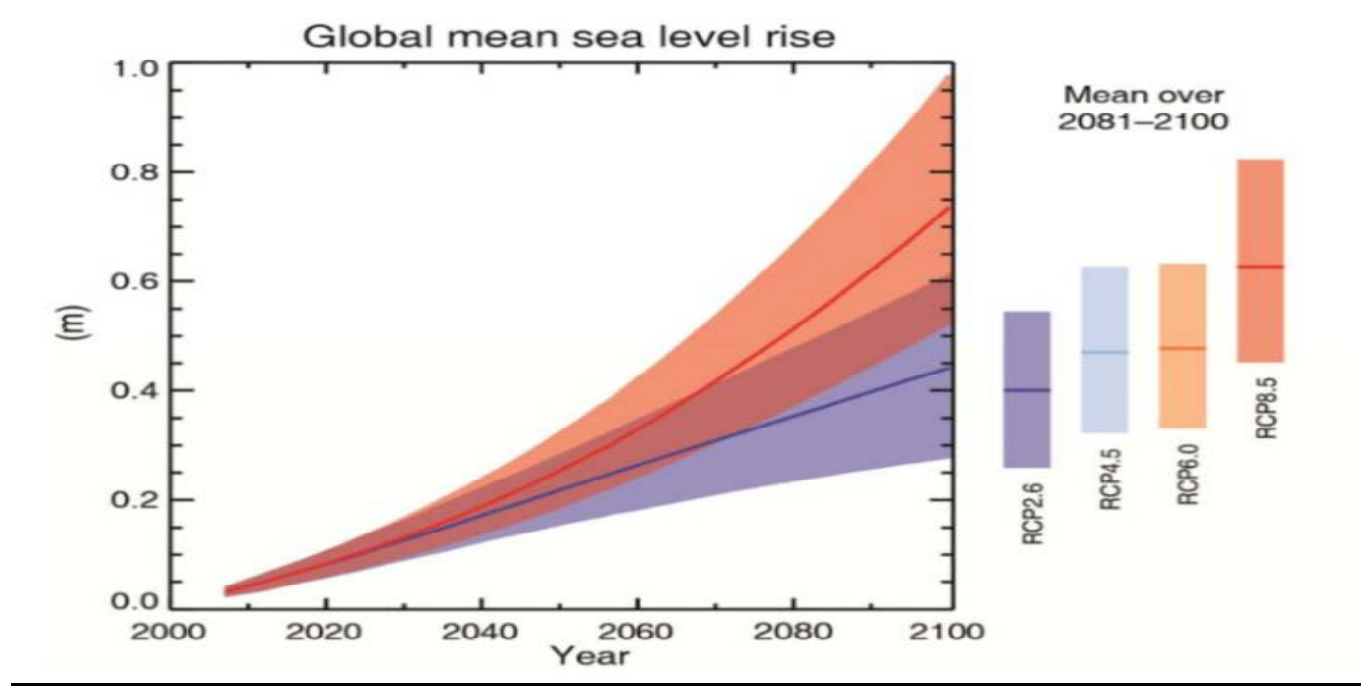

Fuente: IPCC 2014.

Las consecuencias del incremento del nivel del mar en el Magreb serían considerables, especialmente si tenemos en cuenta que los grandes núcleos urbanos y las principales áreas de cultivos mediterráneos (vid, olivo, cítricos, cereales) se concentran en la zona costera 8véase Figura 10). La erosión de las playas, la inundación de zonas de cultivo y la salinización de

\footnotetext{
${ }^{87}$ Werz, Michael y Conley, Laura: "Climate Change, Migration and Conflict in Northwest Africa Rising Dangers and Policy Options Across the Arc of Tension", Center for American Progress (Abril 2012), p. 40.

${ }^{88}$ Climate Change 2014. Impacts, Adaptation, and Vulnerability. Part A: Global and Sectoral Aspects (Working Group II Contribution to the Fifth Assessment Report of the Intergovernmental Panel on Climate Change, IPCC). Cambridge University Press. p. 368. en https://ipcc-wg2.gov/AR5/report/full-report

${ }^{89} \mathrm{Ibid}, \mathrm{p} .369$.

${ }^{90}$ García y Herrero, op. cit.
} 
ríos, bahías y acuíferos incrementarán enormemente la vulnerabilidad de la región durante los próximos años.

Figura 10

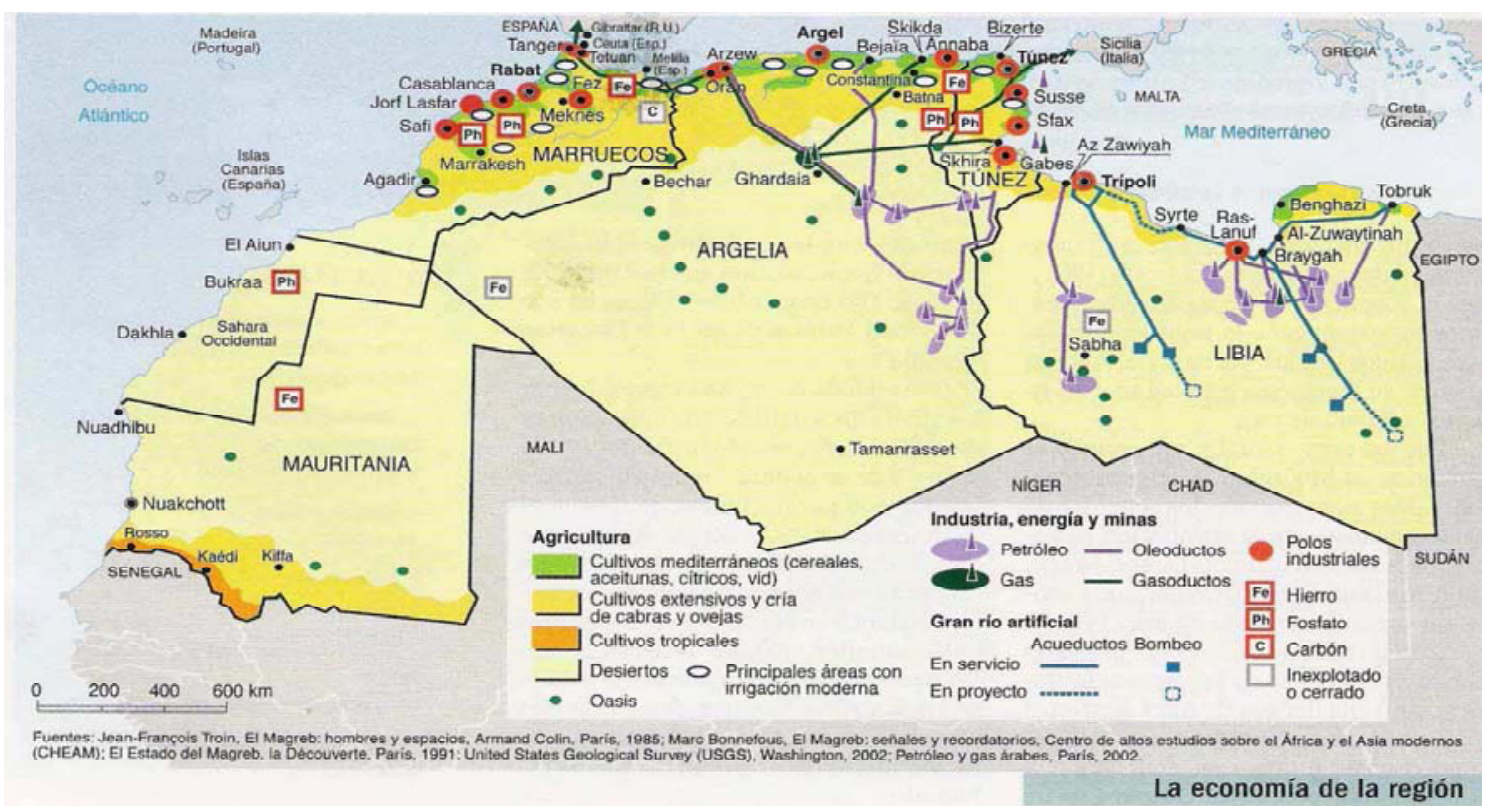

Fuentes: CHEAM, USGS.

\subsubsection{Ecosistemas y biodiversidad}

Los ecosistemas africanos ya están siendo afectados por el cambio climático en la actualidad y se espera que, en el futuro cercano, el impacto sea aún mayor con elevados índices de pérdida de biodiversidad ${ }^{91}$. Los cambios bruscos de temperatura y la degradación medioambiental están provocando transformaciones duraderas en los ecosistemas del Magreb con efectos negativos sobre la fauna y la flora local. Existen indicios de importantes cambios en los ecosistemas terrestres, debido a la pérdida de vegetación y la diseminación de especies, y en los marinos, debido a los cambios en la química de mares y océanos, especialmente el coral, afectando negativamente a la industria pesquera de la región ${ }^{92}$.

La elevada sensibilidad de los animales a las alteraciones del clima dificultará su capacidad de adaptación en la medida en que los cambios no sean graduales, provocando que un gran número de especies, necesarias para la regulación de los ecosistemas, verá aumentado el nivel de riesgo de extinción hasta un $40 \%$ a lo largo de este siglo, especialmente cuando los efectos del cambio climático converjan con otros factores como la polución, la sobreexplotación y la incorporación de especies invasoras ${ }^{93}$.

\footnotetext{
${ }^{91}$ Climate Change 2014. Impacts, Adaptation, and Vulnerability. Part B.., op. cit., p. 1213.

${ }^{92}$ Ibid, p. 1214-1215

${ }^{93}$ Ibid, p. 1214-1218
} 


\section{Figura 11}

(a) Projected biome change from the period 1961-1990 to 2071-2100
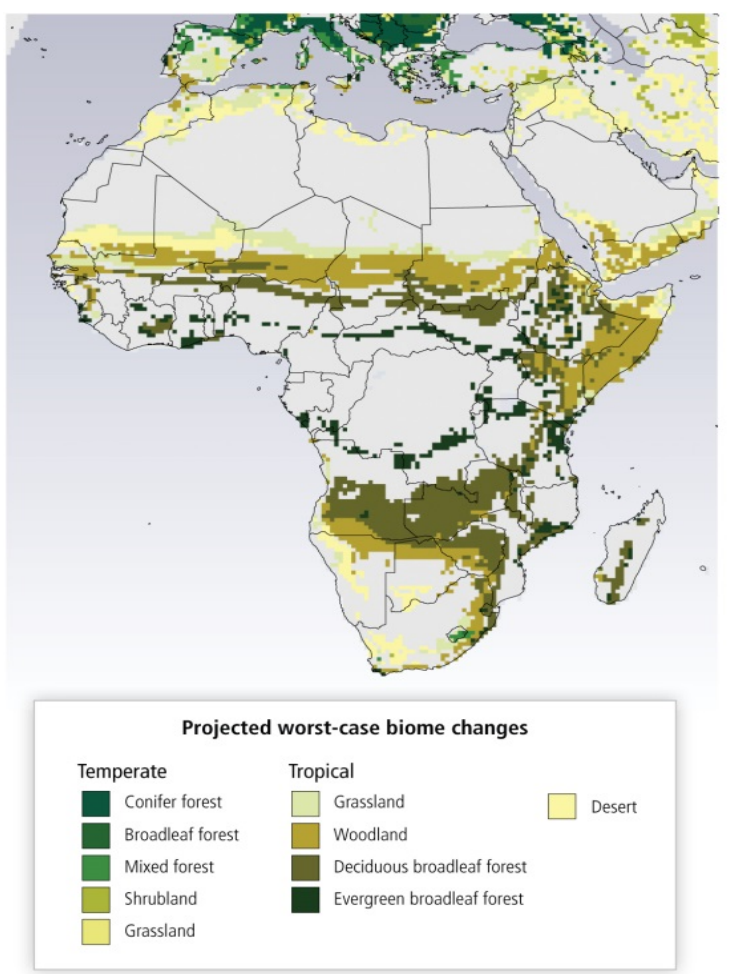

(b) Vulnerability of ecosystems to biome shifts based on historical climate (1901-2002) and projected vegetation (2071-2100)
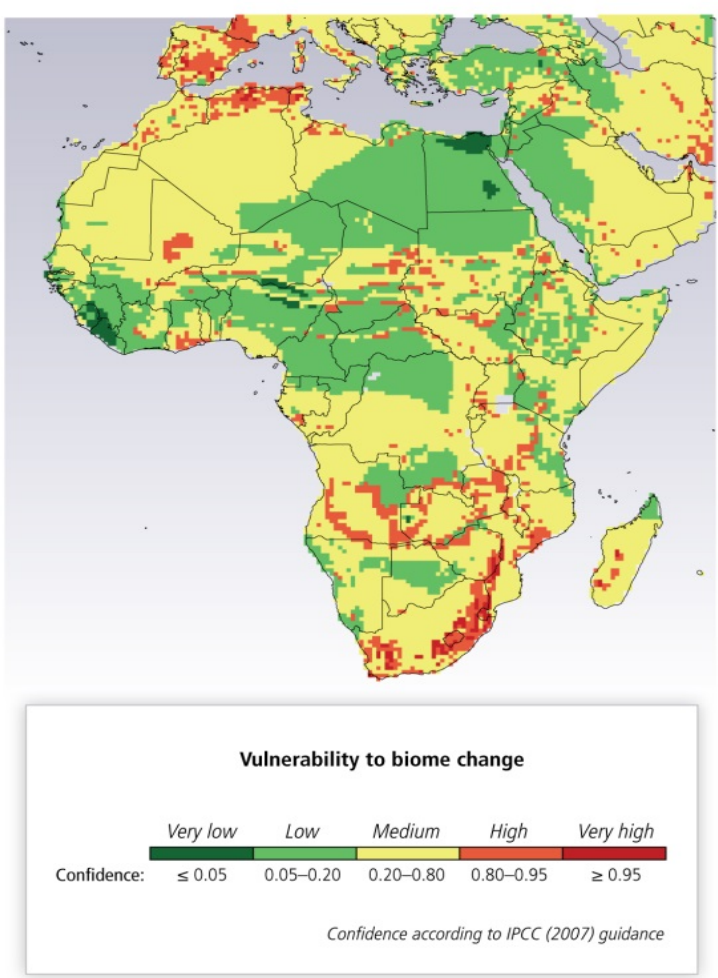

Fuente: Fifth Assessment Report of the Intergovernmental Panel on Climate Change, IPCC

El aumento de temperaturas también está contribuyendo a la degradación de la vegetación regional, especialmente severa cuando se producen elevados niveles de evapotranspiración. La Organización de las Naciones Unidas para la Alimentación y la Agricultura (FAO), ha definido el fenómeno de la evapotranspiración como la suma de las cantidades de agua evaporadas de la superficie y transpiradas desde el tejido vegetal. Dado que tanto evaporación como transpiración suceden simultáneamente y son difíciles de distinguir, el concepto de evapotranspiración pretende definir la cantidad total de agua que pierde un determinado ecosistema, difuminando vapor de agua hacia la atmosfera y estableciendo lo que se denomina como tasa de evapotranspiración ${ }^{94}$.

El cambio climático está provocando un aumento prolongado de la tasa de evapotranspiración, con un impacto negativo sobre la cantidad de agua potable disponible ${ }^{95}$, incrementando la vulnerabilidad de las regiones de climas áridos y semiáridos ${ }^{96}$.

\subsection{Impactos sobre los sistemas humanos}

El impacto del cambio climático sobre el desarrollo económico y la calidad de vida de los habitantes del Magreb tendrán efectos potencialmente devastadores para la región, convirtiéndose en un verdadero riesgo para la seguridad humana. Pobreza, inseguridad

\footnotetext{
94 Alle, Richard G., Pereira, Luis S., Raes, Dirk y Smith, Martin "Crop evapotranspiration - Guidelines for computing crop water requirements", FAO Irrigation and drainage paper 56 (1998).

${ }^{95}$ Climate Change 2014. Impacts, Adaptation, and Vulnerability. Part A.., op. cit., pp. 157-158.

${ }^{96}$ Ibid, p. 80.
} 
alimentaria, migraciones, desplazamientos forzados y empobrecimiento de las condiciones de salud son algunas de las consecuencias más importantes del estrés medioambiental ${ }^{97}$.

\subsubsection{Agricultura y seguridad alimentaria}

Durante los próximos años, la seguridad alimentaria se verá seriamente afectada por el cambio climático y la degradación medioambiental El quinto informe del IPCC reconoce la capacidad del cambio climático para exacerbar las amenazas a la seguridad humana, entre las que destaca la inseguridad alimentaria, un área de especial relevancia en el Magreb ${ }^{98}$. El cambio climático puede afectar a la seguridad alimentaria de diversas formas. La variación en las temperaturas o el régimen de precipitaciones, ya en la actualidad bastante variable, las sequías o inundaciones y la erosión del suelo tienen un impacto directo sobre la disponibilidad de alimentos y la estabilidad del suministro ${ }^{99}$. La disponibilidad de alimentos en los estados del Magreb, de forma especial en Argelia, depende en la actualidad de las importaciones ${ }^{100}$. Está dependencia se incrementará en función no solo del crecimiento de la población sino de la elevada sensibilidad de la producción agrícola a las variaciones del clima, de forma especial en la agricultura de secano, que repercute en la productividad de los cultivos (véase Figura 12), en su calidad e incluso en la infraestructura y los canales de suministro, lo que inducirá, de no producirse medidas de choque con mayores importaciones y subsidios a diversos productos alimenticios, a una subida de los precios de los alimentos amenazando la capacidad de subsistencia de las familias, especialmente en las zonas rurales más pobres ${ }^{101}$.

Figura 12

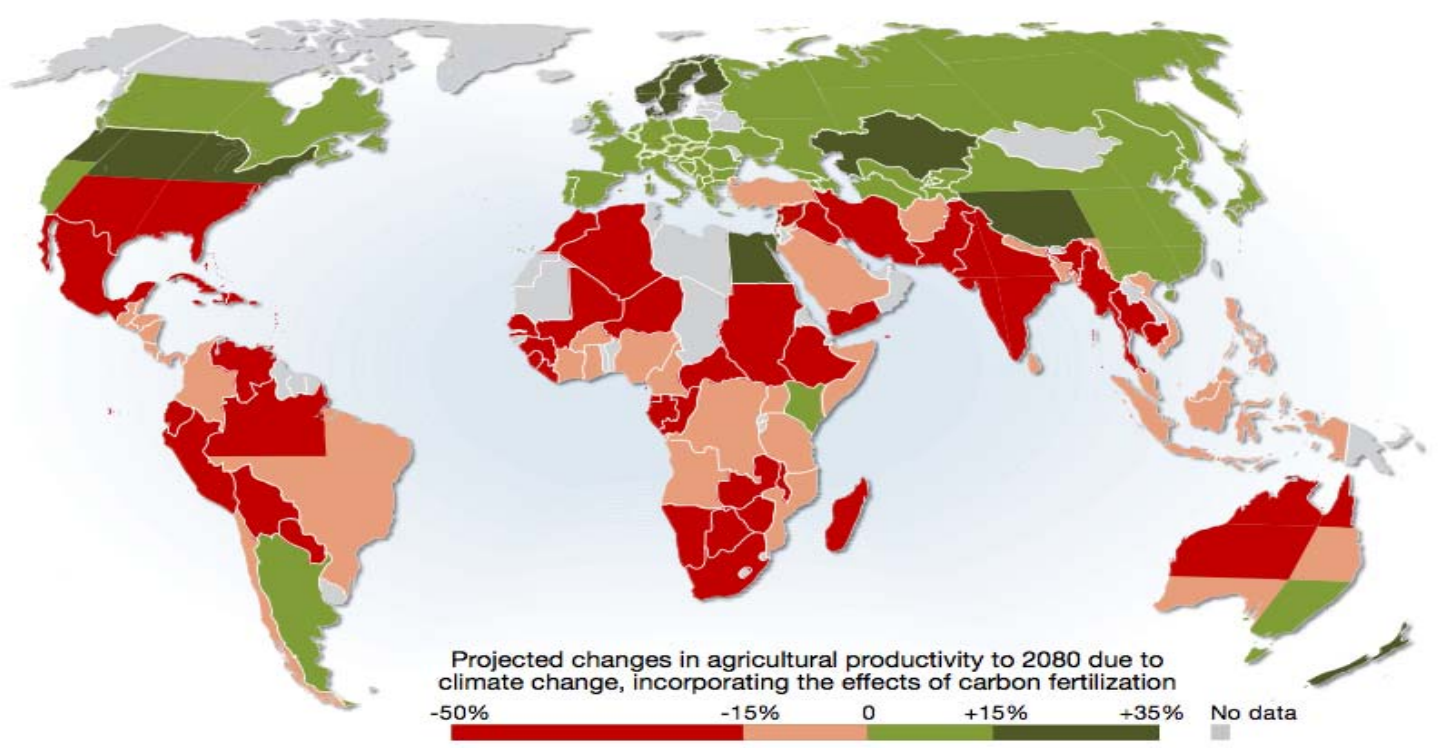

Fuente: Cline 2007.

\footnotetext{
${ }^{97}$ Cambio Climático 2014. Informe de síntesis. Afirmaciones principales del Resumen para responsables de políticas (Grupo Intergubernamental de Expertos sobre el Cambio Climático, IPCC). En http://www.ipcc.ch/news_and_events/docs/ar5/ar5_syr_headlines_es.pdf

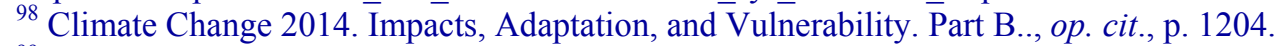

${ }^{99}$ Ibid, p. 1221.

100 Tomando como referencia los años de mayor cifra de importación de alimentos en los estados del Magreb central, a partir de 2010, podemos ver que, según el Banco Mundial, Marruecos en 2012 las importaciones de alimentos supusieron el 12,45 por ciento del total con un desembolso de 44.789 millones de dólares. En el caso de Argelia, en 2014 supusieron el 20 por ciento con un desembolso de 58.330 millones de dólares. Y en el caso de Túnez en 2013 supusieron el 11 por ciento con un desembolso de 24.266 millones de dólares.

${ }^{101}$ Ibid, p. 1221.
} 
El sector agrícola juega un papel fundamental en los países del Magreb, especialmente en Túnez, Argelia y Marruecos, tanto en términos sociales como económicos, con un peso en el PIB que oscila entre el 10\% en caso de Túnez y el 13\% en el caso de Marruecos y con un notable impacto en términos de empleo, ocupando entre el $40 \%$ y el $20 \%$ de la población activa dependiendo del país. Esta dependencia se acentúa aún más en las zonas rurales, donde el total de la población vive exclusivamente de la actividad agrícola.

La variabilidad en el clima, la reducción en la disponibilidad de recursos hídricos y la pérdida de superficie cultivable, derivada de la expansión de la desertización en las zonas de interior y el incremento del nivel del mar en la franja costera, provocará efectos negativos sobre las cosechas de cereales de todo el continente africano. A lo que se añade, como ya indicamos, el avance del desierto del Sáhara que absorbe 40.000 hectáreas de tierra cultivable en Argelia cada año. Marruecos, a su vez, pierde 22.000 hectáreas y Túnez $8.000^{102}$. Se prevé que para los próximos años se producirán caídas de productividad medias de las cosechas de trigo en el Magreb del $17 \%{ }^{103}$, véase Figura 13) llegando en algunas estimaciones hasta el $50 \%$ en el norte de África, incrementando las posibilidades de sufrir hambrunas ${ }^{104}$.

Figura 13

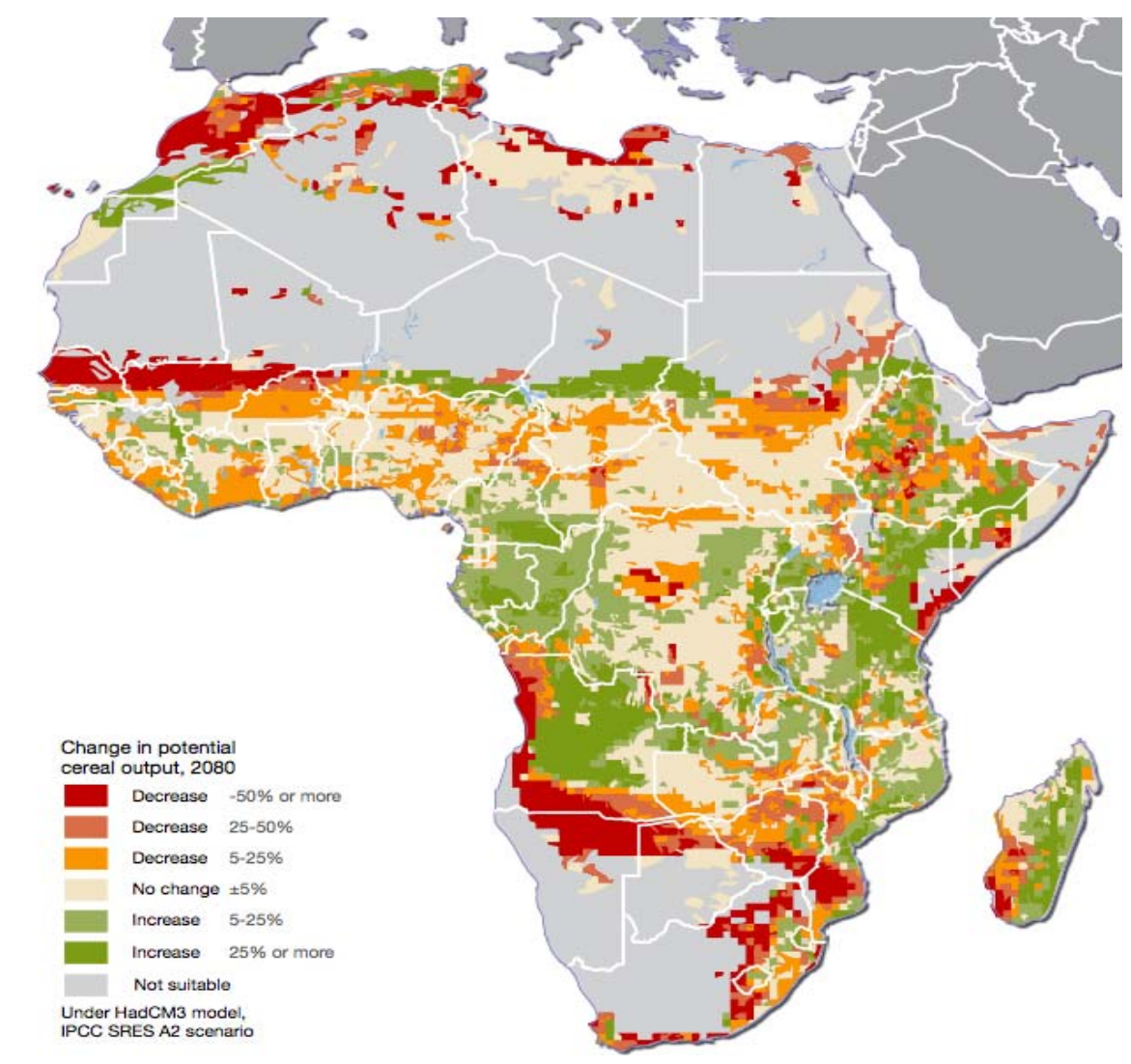

Fuente: Fischer et al., 2005.

\footnotetext{
102 Marquina, op. cit.

${ }^{103}$ Climate Change 2014. Impacts, Adaptation, and Vulnerability. Part A.., op. cit., p. 510.

${ }^{104}$ Clements, Rebecca: "The Economic Cost of Climate Change in Africa", Pan African Climate Justice Alliance (PACJA) (Noviembre 2009), p. 9.
} 


\subsubsection{Condiciones de vida y migraciones medioambientales}

Como consecuencia del cambio climático asistiremos, a lo largo de este siglo, a un empeoramiento general de las condiciones de vida entre los habitantes del Magreb derivado del estrés hídrico, los problemas de salud pública, la presión demográfica sobre las ciudades, resultado de las migraciones internas por el abandono del campo y la disminución del territorio habitable, y la aparición o exacerbación de conflictos por el control de los recursos.

Si bien el cambio climático no es un factor explicativo único de los procesos migratorios ${ }^{105}$, existe cierto consenso acerca de su impacto en las dinámicas de migración a largo plazo que se pueden apreciar en el norte de África como resultado de las presiones del clima $^{106}$. La escasez de recursos hídricos y el avance de la desertización amenazan la supervivencia de las familias en las zonas rurales que dependen de la actividad agrícola para subsistir, provocando desplazamientos hacia la franja costera y aumentando la presión demográfica sobre las ciudades.

Mientras que la escasez de agua y el avance de la desertización provocan desplazamientos permanentes entre los afectados, los fenómenos meteorológicos extremos como sequías e inundaciones suelen causar desplazamientos temporales masivos ${ }^{107}$. Las inundaciones y los corrimientos de tierra que vivió Argelia en el año 2001 afectaron a más de 45.000 personas y a medida que nos vayamos acercando a la mitad del siglo los desastres naturales irán aumentando su frecuencia así como su potencial de disrupción humanitaria ${ }^{108}$.

\section{Costes de adaptación}

La diversidad de modelos de cambio y sus resultados, plantean escenarios diversos en los que los costes de adaptación previsibles, tanto globales como regionales, varían sensiblemente. No obstante, la gran mayoría de estudios realizados en fechas recientes sobre el cambio climático, aceptan la incertidumbre como un elemento inherente a los mismos y con el que hay que contar a la hora de estudiar este fenómeno.

Podemos indicar que los costes de adaptación incluyen ${ }^{109}$ :

- Los costes asociados con acciones tomadas para evitar o minimizar los efectos adversos del cambio climático.

- Los costes directos asociados a los efectos devenidos del cambio climático.

- Los costes indirectos asociados a los efectos devenidos del cambio climático.

Partiendo de esta base, algunas estimaciones, auguran que para 2030, el coste de adaptación anual en África, oscilará entre un mínimo de US\$ 10.000 millones pudiendo alcanzar un coste

\footnotetext{
${ }^{105}$ Climate Change and Migration Evidence from the Middle East and North Africa, Banco Mundial, 2014, pp. 145-146, en http://documentos.bancomundial.org/curated/es/2014/07/19798427/climate-change-migration-evidence-middleeast-north-africa

${ }^{106}$ Véase una evaluación del nexo entre cambio climático y migración y la falta de estudios empíricos en Marquina Antonio:" From a Socioeconomic Approach to Migration to the Inclusion of Environmentally Induced Migration in the Mediterranean" en Marquina Antonio (ed.) (2010): Global Warming and Climate Change. Prospects and Policies in Asia and Europe. Basingstoke, Palgrave Macmillan, pp.187-203.

${ }^{107}$ Ibid, p. 145.

${ }^{108}$ Werz y Conley, op. cit. p. 39.

${ }^{109}$ Clements, op. cit. p. 32.
} 
de hasta 30.000 millones $^{110}$. Otros estudios señalan que el coste para el período $2010-2020$ podría llegar hasta los 60.000 millones de US\$ ${ }^{111}$.

Tabla 2

\begin{tabular}{|l|l|l|}
\hline $\begin{array}{l}\text { Aumento de la } \\
\text { Temperatura }\end{array}$ & Año & $\begin{array}{l}\text { Coste Económico } \\
\text { (porcentaje del PIB) }\end{array}$ \\
\hline $1.5^{\circ} \mathrm{C}$ & 2040 & $1.7 \%$ \\
\hline $2^{\circ} \mathrm{C}$ & 2060 & $3.4 \%$ \\
\hline $4.1^{\circ} \mathrm{C}$ & 2100 & $10 \%$ \\
\hline
\end{tabular}

Fuente: The Economic Cost of Climate Change in Africa.

Las características específicas del Magreb, tales como la escasez de agua, la concentración de la población en áreas costeras y el peso de la agricultura, entre otros, hacen que la región sea especialmente vulnerable a los efectos adversos del cambio climático, por lo que estas especificidades requieren una adaptación específica en sectores clave.

El énfasis principal de la adaptación a las consecuencias del cambio climático en la región recae sobre la escasez de agua ${ }^{112}$. Teniendo en cuenta los datos anteriormente expuestos acerca de la disponibilidad de agua en la región, resulta imprescindible una gran inversión a lo largo y ancho de la región para asegurar un suministro adecuado y suficiente que se adapte tanto a la demanda como a la situación climática del futuro a medio y largo plazo.

La mayor parte de la población del Magreb tiende a concentrarse en las áreas urbanas cercanas a la costa, y es probable que en el futuro próximo esta tendencia se acentúe. Estas áreas son especialmente vulnerables a la subida del nivel del mar ${ }^{13}$ (véase Tabla 3).

Tabla 3

\begin{tabular}{|l|l|l|l|}
\hline ESCENARIO & $\begin{array}{l}\text { Costes totales en } \\
\text { daños residuales } \\
\text { (millones de } \\
\text { US\$/año) }\end{array}$ & $\begin{array}{l}\text { Población } \\
\text { afectada (miles } \\
\text { de personas) }\end{array}$ & $\begin{array}{l}\text { Costes derivados del } \\
\text { aumento del nivel del } \\
\text { mar (millones de } \\
\text { US\$/año) }\end{array}$ \\
\hline Argelia & 328.1 & 35.2 & 328.1 \\
\hline Libia & 186.7 & 3.7 & 167.1 \\
\hline
\end{tabular}

\footnotetext{
${ }^{110} \mathrm{Ibid}$, p. 37.

${ }^{111}$ Banco Africano de Desarrollo: "The Cost of Adaptation to Climate Change in Africa" (October 2011), p.25.

112 Sowers, Jeannie y Weinthal, Erika: "Climate Change Adaptation in the Middle East and North Africa: Challenges and Opportunities", The Dubai Initiative, Working Paper n⿳3 (Septiembre 2010), p. 16.

${ }^{113}$ International Bank for Reconstruction and Development/The World Bank (2014):"Turn Down the Heat: Confronting the New Climate Normal", World Bank Group, Washington, p. 148.
} 


\begin{tabular}{|l|l|l|l|}
\hline Marruecos & 1195.7 & 47.1 & $1,178.0$ \\
\hline Túnez & 722.8 & 17.0 & 710.3 \\
\hline
\end{tabular}

\begin{tabular}{|l|l|l|l|}
\hline ESCENARIO & $\begin{array}{l}\text { Costes totales en } \\
\text { daños residuales } \\
\text { (millones de } \\
\text { US\$/año) }\end{array}$ & $\begin{array}{l}\text { Población } \\
\text { afectada (miles } \\
\text { de personas) }\end{array}$ & $\begin{array}{l}\text { Costes derivados del } \\
\text { aumento del nivel del } \\
\text { mar (millones de } \\
\text { US\$/año) }\end{array}$ \\
\hline Argelia & $6,546.6$ & 435.4 & 916.7 \\
\hline Libia & $1,756.8$ & 39.4 & 477.6 \\
\hline Marruecos & $5,524.3$ & 1820.2 & $3,388.3$ \\
\hline Túnez & $3,459.7$ & 263.9 & $1,798.1$ \\
\hline
\end{tabular}

\begin{tabular}{|l|l|l|l|}
\hline $\begin{array}{l}\text { ESCENARIO } \\
\text { A1F1 }\end{array}$ & $\begin{array}{l}\text { Costes totales en } \\
\text { daños residuales } \\
\text { (millones de } \\
\text { US\$/año) }\end{array}$ & $\begin{array}{l}\text { Población } \\
\text { afectada (miles } \\
\text { de personas) }\end{array}$ & $\begin{array}{l}\text { Costes derivados del } \\
\text { aumento del nivel del } \\
\text { mar (millones de } \\
\text { US\$/año) }\end{array}$ \\
\hline Argelia & $5,238.0$ & 708.1 & $1,454.8$ \\
\hline Libia & $1,325.0$ & 131.2 & 745.2 \\
\hline Marruecos & $5,886.5$ & 2078.9 & $4,001.3$ \\
\hline Túnez & $4,541.0$ & 802.8 & $2,375.0$ \\
\hline
\end{tabular}

Fuente: Turn Down the Heat: Confronting the New Climate Normal ${ }^{114}$.

Asimismo, la agricultura será un sector ampliamente castigado, sin que pueda calcularse la magnitud exacta de los costes. No obstante, en un escenario de aumento de las temperaturas de $2^{\circ} \mathrm{C}$ contrapuesto a un aumento de $4^{\circ} \mathrm{C}$, se consideran altamente probables las siguientes consecuencias $^{115}$ :

- Un desplazamiento hacia el norte de las áreas de cultivo (hasta $75 \mathrm{~km}$ en el escenario de aumento de $4^{\circ} \mathrm{C}$ ).

- Una disminución del período anual de crecimiento de cultivos: un acortamiento de 10 días en un escenario de aumento de $1.3^{\circ} \mathrm{C}$, de 16 días en un escenario de aumento de $2^{\circ} \mathrm{C}$, de 20 días en un escenario de aumento de $2.5^{\circ} \mathrm{C}$, y de 30 días en un escenario de aumento de $4^{\circ} \mathrm{C}$.

\footnotetext{
${ }^{114}$ Las proyecciones aquí presentadas son progresivas hasta el año 2100.

${ }^{115}$ International Bank for Reconstruction and Development/The World Bank, op. cit., p. 113.
} 
- Un descenso en el volumen de las cosechas: de aproximadamente el 30\% en un escenario de aumento de temperaturas de $1.5-2^{\circ} \mathrm{C}$, y de hasta el $60 \%$ si éstas aumentan $3-4^{\circ} \mathrm{C}$.

\section{Conclusiones}

A raíz de todo lo expuesto anteriormente, cabe señalar que el cambio climático y sus consecuencias suponen ya un problema de primer orden para la seguridad de los estados y los individuos. Es innegable que ya no se puede contemplar el cambio climático como un potenciador de riesgos y amenazas, sino como un riesgo en sí mismo, que, tanto en materia climatológica como económica y demográfica, tiene el potencial de superar en impacto y consecuencias a cualquier otro riesgo o amenaza a nivel regional.

No obstante, no se puede perder de vista que las consecuencias del cambio climático están estrechamente relacionadas con otros problemas, como conflictos nacionales e internacionales, migraciones, cuestiones como la seguridad alimentaria y otros problemas, que se irán agravando progresivamente creando una espiral de deterioro difícilmente controlable dados los costes de la adaptación. Las consecuencias del cambio climático tendrán impactos negativos en aspectos básicos para la supervivencia humana: la disponibilidad de agua potable, de alimentos o los medios para auto-procurárselos, la inhabitabilidad del territorio que provocará migraciones masivas agravando conflictos preexistentes, etc.

Es por eso que este debe ser uno de los principales puntos a tratar por las agendas de seguridad regionales y nacionales, y también uno de los principales focos de colaboración internacional Norte-Sur. La Unión Europea ha reconocido la necesidad de priorizar la cooperación con el Magreb en la medida en que la región es un área de seguridad de especial relevancia para Europa. En este sentido la U.E. ha lanzado algunas iniciativas, tales como Horizon 2020 y Clima South, que hasta el momento no han tenido resultados tangibles ni dado fruto a inversiones en este ámbito ${ }^{116}$.

En la región del Magreb, así como en el mundo Árabe en general, la climatología siempre ha tenido una especial relevancia a la hora de elaborar políticas de gestión de recursos. El agua es ya un elemento de principal preocupación en la región. Las políticas de gestión de recursos hídricos en el Magreb se han enfocado hacia dos vertientes fundamentales: la gestión y almacenamiento de los recursos ya existentes, y la explotación y desarrollo de nuevas fuentes de agua. Los datos analizados dejan ver que los recursos existentes no serán suficientes para satisfacer una demanda de agua creciente y aunque las nuevas tecnologías, especialmente las enfocadas hacia la desalinización, ofrecen perspectivas prometedoras, está aún por ver si los gobiernos regionales son capaces de asumir las inversiones necesarias, así como los impactos medioambientales colaterales inherentes a la implantación de estas tecnologías.

Por último, es fundamental considerar que los países del Magreb son estados que aún no están plenamente desarrollados, por lo que los gobiernos nacionales deben ponderar que cantidad de los limitados recursos de sus presupuestos nacionales pueden invertir en garantizar la sostenibilidad medioambiental de sus políticas. Además existe el agravante de que Libia y Argelia tienen una gran dependencia económica de los combustibles fósiles, en conflicto directo con las necesidades de sostenibilidad medioambiental que ya se están proponiendo.

${ }^{116}$ Véase el artículo de Xira Ruiz en esta revista. 